\title{
Flora da Paraíba, Brasil: Solanum L. (Solanaceae)
}

\author{
Maria de Fátima Agra ${ }^{1,2}$, Kiriaki Nurit-Silva ${ }^{1}$ e Lúcia Raquel Berger ${ }^{1}$
}

Recebido em 3/03/2008. Aceito em 11/12/2008

RESUMO - (Flora da Paraíba, Brasil: Solanum L. (Solanaceae)). Neste trabalho apresenta-se o tratamento taxonômico do gênero Solanum, como parte do projeto "Flora da Paraíba", que vem sendo realizado com o objetivo de identificar e catalogar as espécies da flora local. Realizaram-se coletas, observações de campo e estudos morfológicos para as identificações, descrições e ilustrações botânicas, com o auxílio da bibliografia especializada, complementadas pela análise de tipos e fotos de tipos de herbários nacionais e internacionais e de espécimes depositados nos herbários EAN e JPB. Foram registradas 22 espécies: Solanum agrarium Sendtn., S. americanum Mill., S. asperum Rich., S. asterophorum Mart., S. caavurana Vell., S. capsicoides All., S. crinitum Lam., S. jabrense Agra \& M.Nee, S. melissarum Bohs, S. ovum-fringillae (Dunal) Bohs, S. palinacanthum Dunal, S. paludosum Moric., S. paniculatum L., S. paraibanum Agra, S. polytrichum Moric., S. rhytidoandrum Sendtn., Solanum sp., S. stagnale Moric., S. stipulaceum Roem. \& Schult., S. stramoniifolium Jacq., S. swartzianum Roem. \& Schult. e S. torvum Sw. Três espécies, S. ovum-fringillae, Solanum sp. e S. swartzianum, são novas referências para a Paraíba. Palavras-chave: Flora paraibana, Jurubeba, Nordeste brasileiro

ABSTRACT - (Flora of Paraíba, Brazil: Solanum L. (Solanaceae)). A taxonomic treatment of the genus Solanum was done as part of the project "Flora da Paraíba", which aims to identify and catalogue the species of the local flora. Botanical collections, field observations and morphological studies were done for identification, description and botanical illustration of the plant species, supported by the literature and analysis of national and foreign herbaria, and specimens from EAN and JPB. Twenty two species of Solanum were recorded in State of Paraíba, as follows: Solanum agrarium Sendtn., S. americanum Mill., S. asperum Rich., S. asterophorum Mart., S. caavurana Vell., S. capsicoides All., S. crinitum Lam., S. jabrense Agra \& M.Nee, S. melissarum Bohs, S. ovum-fringillae (Dunal) Bohs, S. palinacanthum Dunal, S. paludosum Moric., S. paniculatum L., S. paraibanum Agra, S. polytrichum Moric., S. rhytidoandrum Sendtn., Solanum sp., S. stagnale Moric., S. stipulaceum Roem. \& Schult., S. stramoniifolium Jacq., S. swartzianum Roem. \& Schult. and S. torvum Sw. Three species are new records for Paraíba: S. ovum-fringillae, Solanum sp. and S. swartzianum.

Key words: Flora paraibana, "Jurubeba", Northeastern Brazil

\section{Introdução}

A família Solanaceae A. L. Jussieu está constituída de cerca de 106 gêneros (Olmstead et al. 1999) e 2.300 espécies, com distribuição cosmopolita, sendo a América do Sul como um dos principais centros de diversidade e endemismo (Hunziker 2001).

Solanum L. é o maior gênero de Solanaceae, com cerca de 1.400 espécies (Bohs 2005) e 5.000 epítetos descritos (Nee 1999). O gênero possui ampla distribuição em todo o mundo, sendo o Brasil, especialmente a região Sudeste, um dos centros de diversidade genética de vários grupos infragenéricos de Solanum subg. Leptostemonum (Whalen 1984) e de Solanum seções Acanthophora (Nee 1979; 1991), Brevantherum (Roe 1972), Cernuum e Lepidotum (Carvalho 1996), Erythrotrichum (Agra 2004), Crinitum e Polytrichum (Agra 2007).

O gênero apresenta-se como um grupo bem caracterizado, apesar da diversidade existente. Sua uniformidade pode ser reconhecida pelo perianto e androceu pentâmeros, estames coniventes, anteras amarelas, oblongas ou atenuadas da base para o ápice e deiscência poricida (Roe 1972). Todavia, as espécies das seções Androceras, Normania, Anisantherum e Nycterium são heterandras, com maior alongamento dos filetes ou das anteras (Lester et al. 1999).

Com relação à classificação infragenérica do grupo, desde sua proposição por Linnaeus (1753), o autor dividiu Solanum em dois grupos, inermia e spinosa. Vários tratamentos subsequientes foram propostos, com base na presença ou ausência de acúleos, morfologia das anteras e das inflorescências, caracteres constantes no gênero e ainda usados nos sistemas atuais de classificação.

Atualmente, os estudos moleculares com Solanaceae (Olmstead et al. 1999) e Solanum (Olmstead \& Palmer 1997; Levin et al. 2006) intensificaram-se e, como conseqüência, as posições intergenéricas de alguns táxons estão sendo alteradas, como a inclusão de Lycopersicon e Cyphomandra em Solanum, com base nos estudos de Spooner et al. (1993) e Bohs (1995), respectivamente. Estes estudos têm proporcionado uma visão mais detalhada da filogenia da família e contribuído para elaborar uma hipótese filogenética mais abrangente para Solanum.

No Brasil, o tratamento mais abrangente para Solanum foi realizado por Sendtner (1846), que descreveu 170 espécies para o país e, pela primeira vez, usou a morfologia do indumento como uma característica adicional para a separação de táxons infragenéricos. Outras informações sobre o gênero são encontradas em floras e listas regionais: Smith \& Downs (1966), Carvalho (1985), Agra (1999a; 2006; 2007), Agra et al. (2003), Stannard (1995), Mentz \& Oliveira (2004), Carvalho \& Bovini (2006), e em descrições de novas espécies para várias regiões do país: Knapp (1989; 2002), Agra (1992; 1999b), Agra \& Nee (1997), Carvalho (1996), Mentz \& Nee (2003a; b).

Para a Paraíba, estudos farmacobotânicos foram realizados com algumas espécies de Solanaceae (Nurit \& Agra 2005; Nurit et al. 2007a; b) e um tratamento para o gênero Schwenckia (Sousa et al. 2004), entretanto, nenhum

\footnotetext{
1 Universidade Federal da Paraíba, Laboratório de Tecnologia Farmacêutica Prof. Delby Fernandes de Medeiros, Setor de Botânica, João Pessoa, PB, Brasil

2 Autor para correspondência: agramf@1tf.ufpb.br
} 
tratamento taxonômico foi realizado para Solanum. As informações sobre o gênero na área são registradas em dois levantamentos florísticos: Agra et al. (2004) e Barbosa et al. (2004).

Este trabalho teve como objetivo o tratamento taxonômico do gênero Solanum, dando continuidade aos estudos que estão sendo desenvolvidos para o projeto "Flora da Paraíba" (Cabral \& Agra 1999; Pontes \& Agra 2006; Pontes et al. 2004; Sousa et al. 2004; Nurit et al. 2005; Loiola et al. 2007).

\section{Material e métodos}

Área de estudo - O Estado da Paraíba está situado na porção oriental do Nordeste brasileiro, entre os meridianos de $34^{\circ} 45^{\prime} 54^{\prime \prime}$ e $38^{\circ} 45^{\prime} 45^{\prime \prime}$ longitude oeste e os paralelos de 6 02 ' 12 "' e $8^{\circ} 19^{\prime} 18^{\prime \prime}$ latitude sul, ocupando uma área de $56.372 \mathrm{~km}$ (Moreira 1985). O clima é quente e úmido no litoral, com temperaturas médias anuais oscilando entre 24 e $27{ }^{\circ} \mathrm{C}$, com pluviosidade de 900 a $1.800 \mathrm{~mm}$ ao ano e umidade relativa em torno de $80 \%$. A maior parte do território, entretanto, pertence ao domínio quente e seco, semi-árido. Nesta área, registram-se altas médias mensais de temperatura, de 25 a $30^{\circ} \mathrm{C}$, e baixos índices pluviométricos, de 300 a $1.000 \mathrm{~mm}$ anuais, caracterizados por uma má distribuição dos totais anuais, o que condiciona a presença de uma vegetação fortemente xerofítica (Lima \& Heckendorff 1985). A cobertura vegetal varia de acordo com as condições ambientais e geomorfológicas, sendo encontrados no litoral matas de restinga, manguezais, manchas de cerrado e remanescentes de mata atlântica e no interior agreste, caatinga e enclaves de matas serranas (Carvalho \& Carvalho 1985).

Identificações e descrições - Realizaram-se estudos morfológicos para as identificações com amostras frescas, fixadas em FAA e conservadas em álcool a $70^{\circ}$, e análise de exsicatas dos herbários JPB e EAN, ambos da Universidade Federal da Paraíba, e IPA, Empresa Pernambucana de Pesquisa de Agropecuária, complementados por observações de campo. Os estudos taxonômicos foram realizados com o apoio da bibliografia especializada (Sendtner 1846; Dunal 1852; Edmonds 1972; 1977; Bohs 1994; Carvalho 1996; Knapp 2002; Mentz \& Oliveira 2004; Agra 2004), complementados pela análise de espécimes e tipos dos herbários EAN, CEPEC, F, G, IPA, K, M, MAC, MG, MO, NY, P, R, RB, PEUFR, S, SP e SP, SPF, UB, US e W, relacionados de acordo com Holmgren et al. (1990). As descrições de algumas espécies, cujo material encontrava-se estéril ou incompleto, foram complementadas pela análise de material adicional. Os estudos das partes reprodutivas e as ilustrações foram realizados com o auxílio do estéreomicroscópio e câmara-clara, Zeiss. O material coletado encontra-se depositado no herbário JPB e na coleção de referência do Laboratório de Tecnologia Farmacêutica Prof. Delby Fernandes de Medeiros (LTF). As abreviaturas dos nomes dos autores estão de acordo com Brummitt \& Powel (1992). O tratamento taxonômico seguiu o modelo proposto para a flora paraibana (Cabral \& Agra 1999).

\section{Resultados e discussão}

\author{
Solanum L., Sp.Pl. 1: 184-188. 1753.
}

Ervas, arbustos, árvores, lianas, raramente epífitas, aculeadas ou inermes, glabras ou pubescentes com uma variedade de tricomas simples, ramificados, estrelados, peltados, glandulares, algumas vezes cerdosos. Folhas alternas, simples ou compostas, isoladas, aos pares ou fasciculadas, inteiras a lobadas, denteadas, partidas, desde glabras a denso-pilosas, com tricomas eglandulares, glandulares ou estrelados, aculeadas ou inermes, pecioladas ou sésseis. Inflorescência terminal, axilar, lateral ou opositifolia, consistindo de cimeiras simples (escorpióide) ou ramificada, ou contraída (umbeladas). Flores geralmente monoclinas, algumas vezes monóicas, raramente dióicas, actinomorfas, pentâmeras ou tetrâmeras. Cálice campanulado, 5-lobado, muitas vezes acrescente no fruto. Corola rotácea ou rotáceo-estrelada, tubo inconspícuo, lobos levemente a profundamente lobados; 5 estames, iguais ou anisostêmones, coniventes, filamentos inseridos no tubo da corola, parcialmente conatos, raramente sésseis, anteras basifixas ou dorsifixas, oblongas ou atenuadas, abrindo por 2 poros terminais, deiscência introrsa ou extrorsa; ovário 2-locular, pluriovulado, estilete igual ou geralmente acima das anteras, estigma pequeno ou 2-4-lobado. Baga suculenta, mucilaginosa, esférica ou ovóide; sementes numerosas, discóides, reniformes, suborbiculares, ás vezes aladas, testa lisa ou ornamentada, parda ou negra.

Na Paraíba, o gênero está representado por 22 espécies: Solanum agrarium Sendtn., S. americanum Mill., S. asperum Rich., S. asterophorum Mart., S. caavurana Vell., S. capsicoides All., S. crinitum Lam., S. jabrense Agra \& M.Nee, S. melissarum Bohs, S. ovum-fringillae (Dunal) Bohs, S. palinacanthum Dunal, S. paludosum Moric., S. paniculatum L., S. paraibanum Agra, S. polytrichum Moric., S. rhytidoandrum Sendtn., Solanum sp., S. stagnale Moric., S. stipulaceum Roem. \& Schult., S. stramoniifolium Jacq., S. swartzianum Roem. \& Schult. e S. torvum Sw. Três espécies, S. ovum-fringillae, S. swartzianum e S. arenarium, são novas referências para a área de estudo.

\section{Chave para identificação das espécies de Solanum da Paraíba}

1. Plantas inermes; anteras oblongas ou lanceoladas, atenuadas para o ápice, com o conectivo ampliado na base

2. Ervas ou arbustos, ramos e folhas glabros ou glabrescentes, tricomas simples e ramificados; inflorescências em cimeiras simples; baga glabra

3. Ervas, flores menores que 1,0 cm; baga globosa, negra, 4,0-7,0 mm diâm.

1. S. americanum

3. Arbustos a arvoretas, flores maiores que $1,0 \mathrm{~cm}$; baga ovóide ou obovóide, verde-amarelada quando madura, 1,5-2,5 cm diâm.

4. Cimeiras escorpióides; corolas lilases ou alvo-esverdeadas, profundamente partidas; anteras com o conectivo ampliado na base, vermelho ou arroxeado

5. Folhas elípticas a oval-elípticas, cálice campanulado, membranáceo; corola esverdeada, membranácea; conectivo arroxeado 10. S. melissarum

5. Folhas ovais ou cordiformes, cálice urceolado-radiado, crasso; corola lilás a púrpura, levemente carnosa; conectivo avermelhado 
4. Cimeiras helicóides; corola alva a esverdeada, partida até a metade; anteras amarelas, sem o conectivo ampliado na base

6. Folhas pilosas nas faces adaxial e abaxial, tricomas simples e ramificados, cálice sem espessamento dorsal

6. Folhas glabras na face adaxial e com tufos de tricomas simples na nervura principal da face abaxial, cálice com espessamento dorsal na base dos lobos

2. Arbusto ou árvore; ramos e folhas tomentosos, velutinos ou lepidotos, tricomas estrelados ou peltados; inflorescências em cimeiras simples ou ramificadas; baga glabra ou pubescente

7. Árvore; ramos e folhas lepidotos, dourado-claro ou castanho, tricomas peltados; baga glabra, cálice frutífero acrescente envolvendo parcialmente o fruto 21. S. swartzianum

7. Arbusto; ramos e folhas ásperas, tomentosas ou velutinas, verdes ou cinéreas, tricomas porrectoestrelados; baga pubescente não envolvida pelo cálice acrescente

8. Ramos sem pseudoestípulas; folhas ásperas, brilhantes; corola alva

8. Ramos com pseudoestípulas; folhas velutinas, cinéreas, opacas; corola lilás ou púrpura

19. S. stipulaceum

1. Plantas aculeadas; anteras lanceoladas ou linear-lanceoladas, atenuadas para o ápice, sem o conectivo ampliado na base

9. Lianas; ramos e folhas com acúleos fortemente recurvos no ápice; baga maior de 3,0 cm, amarelo-laranja, hirsuta

9. Subarbustos, arbustos ou arvoretas; ramos e folhas com acúleos aciculares, cônicos ou comprimidos na base e recurvos no ápice; baga sem os caracteres acima

10. Subarbustos ou arbustos; baga com epicarpo glabro

11. Plantas com a ramificação simpodial difoliada; inflorescências em cimeiras simples, 2-20 flores; corola alva ou esverdeada

12. Ramos em zig-zag; lâmina foliar com tricomas estrelados, curtos ou longo-estipitados, amarelados a ferrugíneos; baga parcial ou completamente envolvida pelo cálice acrescente

13. Folhas subinermes, face adaxial escabra a tomentosa, castanho-escuro a nigrescente, tricomas porrecto-estrelados; corola rotáceo-estrelada, alva; baga parcialmente envolvida pelo cálice acrescente

5. S. asterophorum

13. Folhas com acúleos aciculares, amarelados, face adaxial hirsuta, amarelo-ferrugínea a rubiginosa, tricomas estrelados, longo-estipitados; corola estrelada, alva a esverdeada; baga envolvida pelo cálice acrescente, inflado.....

16. S. polytrichum

12. Ramos eretos; lâmina foliar com tricomas simples em pelo menos uma das faces; baga não envolvida pelo cálice acrescente

14. Fruto com epicarpo vermelho-laranja; sementes aladas; corola alva

7. S. capsicoides

14. Epicarpo amarelo ou esverdeado; sementes não aladas; corola roxa, lilás ou amareloesverdeada

15. Inflorescência com 2-3 flora; corola amarelo-esverdeada; sementes reniformes

15. Inflorescência com 5-10 flora; corola púrpura, lilás ou violácea; sementes lentiformes

12. S. palinacanthum

11. Plantas com a ramificação simpodial plurifoliada; inflorescências em cimeiras ramificadas, 30-multi-flora; corola alva, lilás ou cerúlea

16. Folhas e ramos com indumento castanho; cálice com tricomas glandulares; corola alva

16. Folhas e ramos com indumento cinéreo a alvacento; cálice com tricomas estrelados; corola cerúlea ou lilás

10. Arbustos a arvoretas; baga com epicarpo tomentoso, víscido-tomentoso; tricomas decíduos ou persistentes

17. Plantas com a ramificação simpodial plurifoliada; baga com epicarpo víscido-tomentoso, tricomas glandulares e estrelado-glandulares, persistentes

18. Inflorescência em cimeira simples, 5-15-flora; corola lilás ou violácea

19. Folhas subinermes; lâmina oval-eliptica, aguda na base, face adaxial com tricomas porrecto-estrelados, esparsos; epicarpo com tricomas glandulares e estrelado-glandulares 
19. Folhas com acúleos aciculares; lâmina lanceolada a oval-cordiforme, cordiforme na base, face adaxial tomentosa, tricomas estrelados com o raio central pluricelular, glandular apical; epicarpo com tricomas glandulares

18. Inflorescência em cimeira ramificadas, 20-multiflora; corola alva 17. S. rhytidoandrum

17. Plantas com a ramificação simpodial difoliada; baga com epicarpo tomentoso ou hirsuto, tricomas estrelados, decíduos ou persistentes

20. Baga com 1,2-1,5 cm diâm., epicarpo tomentoso, tricomas estrelados, decíduos ao tato; corola alva, 1,5-2,0 cm diâm. 20. S. stramoniifolium

20. Baga com 2,5-5,0 cm diâm., epicarpo hirsuto, tricomas estrelados, persistentes; corola púrpura, lilás ou cerúlea, 2,5-7 cm diâm.

21. Folhas largo-oval a elípticas, lobadas ou repandas, lâmina não decurrente no pecíolo; baga com 4,0-5,0 cm diâm.; corola pentagonal-rotácea, púrpura ou lilás, 4,0-7,0 cm diâm. 8. S. crinitum

21. Folhas oval-elípticas, lâminas decurrentes no pecíolo; baga com 2,5-3,0 cm diâm., corola estrelada, cerúlea, 3,0-4,0 cm diâm. 18. S. stagnale

1. Solanum agrarium Sendtn., in Martius, Fl. bras. 10: 69, pl. 5, f. 32-33. 1846.

Fig. 1-3, 46

Subarbusto a arbusto, ereto a levemente prostado, 0,5-0,7 m alt., fortemente aculeado; caule e ramos cilíndricos, tricomas simples e estrelados esparsos, acúleos aciculares, 0,2-1,0 cm. Folhas simples, pecíolo 1,0-4,0(-6,0) cm compr., cilíndrico, lâmina 3,0-6,0×2,0-5,0 cm, membranácea a cartácea, oval a oval-elíptica, 1-5 pares de lobos, agudos, obtusos ou arredondados, ápice agudo ou obtuso, base assimétrica ou sub-cordada, acúleos aciculares na venação principal, 0,2-0,6 cm, face adaxial com tricomas simples, glandularestipitados e eglandulares, face abaxial com tricomas estrelados, sésseis. Inflorescência em cimeira, 2-3-flora, pedúnculo 2,0-3,0 $\mathrm{mm}$ compr., pedicelo 1,0-1,5 cm compr., acúleos 1,0-2,0 mm compr., aciculares. Flores monoclinas e estaminadas, cálice campanulado, membránaceo, estreladopiloso externamente, sépalas soldadas no $1 / 3$ basal, tubo 1,0-1,2 mm compr., lobos 3,0-4,0 mm compr., irregularmente triangulares, com ou sem acúleos; corola estrelada, amareloesverdeada, 2,0-2,5 cm diâm., pétalas soldadas no 1/4 basal, tubo 2,0-3,0 mm, lobos 7,0-10×2,0-2,5 mm, oblongolanceolados; filetes 0,8-1,0 mm compr., anteras 4,0-5,0 mm compr., lanceoladas; ovário globoso, 1,0-1,2 mm diâm., pubérulo, tricomas glandular-estipitados, estilete 7,0-7,5 mm compr., 1,0-2,0 mm compr. nas flores estaminadas. Baga globosa, 2,0-2,5 cm diâm., não envolvida pelo cálice frutífero, aculeado, epicarpo fosco, verde-variegado a amarelo-claro, glabro; pedicelo frutífero deflexo, 15,0-20,0×1,6-1,8 mm aculeado, estrelado-pubescente; sementes numerosas, 2,5-3,0×2,0-2,5 mm, reniformes, não aladas, comprimidas, beges.

Espécie neotropical, encontrada em áreas quentes e secas da Colômbia, Venezuela, Antilhas Holandesas e Caribe, com disjunção no Brasil, encontrada especialmente na região nordeste (Nee 1991). Na Paraíba, foi encontrada no litoral e na caatinga, ocorrendo em pastagens, beiras de estradas e terrenos baldios, em solos arenosos e argilo-arenosos, ao nível do mar (Agra 1338) e em elevações acima de $700 \mathrm{~m}$ (Agra \& Barbosa 1863).
Material examinado: BRASIL. Paraíba: Alagoinha, 8/IX/1942, fl., Milanez 862 (JPB); Araruna, III-IV/2003, fl. fr., Agra et al. 6249(JPB); Areia, 30/X/1944, fl. fr., Vasconcelos 359 (EAN, RB); VII/1993, fl., A gra 1764 (JPB); Cabaceiras, 23-25/VI/1993, fl. fr., A gra et al. 2076 (JPB); 29-30/VI/1994, fl., Agra et al. 3010, 3054 (JPB); Caldas Brandão, 18/III/1980, fl. fr., Agra 246 (JPB); Campina Grande, 25/VI/1996, fl. fr., Agra et al. 3709, 3717 (JPB); Catolé do Rocha, 12/V/1982, fl. fr., Miranda 74 (JPB); Ingá, X/1993, fl. fr., Agra \& Rocha 2167 (JPB); Itaporanga, 24/III/1993, fr., Agra et al. 1721 (JPB); João Pessoa, 22/XI/1991, fr., Agra 1331 (JPB); 10/X/1991, fl. fr., Agra 1338 (JPB); 4/XI/1993, fr., Moura 1095 (JPB); Maturéia, 2-3/IV/1991, fl. fr., Agra \& Barbosa 1863 (JPB); Nazarezinho, 23/IV/1982, fl. fr., Sousa 1193 (JPB); Patos, 26/V/1993, fl. fr., Agra \& Fragoso 2122 (JPB); Santa Rita, VII/1990, fr., Agra 1291 (JPB); São João do Cariri, 27-29/IV/1994, fl. fr., Agra et al. 2974 (JPB); Solânea, 2/VIII/2001, fl. fr., Grisi 284 (JPB); Vieirópolis, 15///2000, fl. fr., Agra \& Sarmento 5563 (JPB).

2. Solanum americanum Mill., Gard. Dict. ed. 8, nº5. 1768. Fig. $4-8,46$

Erva ereta, 0,6-0,8 m alt., inerme; caule e ramos cilíndricos, raro angulosos, glabrescentes, tricomas simples, glandulares e eglandulares, inermes. Folhas basais solitárias e as apicais geminadas, pecíolo 0,5-2,0 cm compr., parcialmente atenuado, lâmina 2,0-15×2,0-6,0 cm, membranácea, oval a ovallanceolada, ápice agudo a acuminado, base arredondada, decurrente no pecíolo, inerme, ambas as faces com tricomas simples, glandular-estipitados e eglandulares, esparsos, adpressos. Inflorescência em cimeira, 3-8-flora, pedúnculo 1,0-2,5 cm compr.; pedicelo 2,0-4,0 mm compr., estriado. Flores monoclinas, cálice campanulado, membranáceo, puberulo, tricomas semelhantes aos das folhas, 5-lobado, sépalas soldadas até a metade, tubo 0,9-1,0 mm compr., lobos deltóides, 0,9-1,0 mm compr.; corola estrelada, alva, tubo 1,2-1,5 mm compr., lobos 2,5-3,0 mm compr., oblongolanceolados; filetes $0,7-1,0 \mathrm{~mm}$ compr., anteras $1,0-1,5 \mathrm{~mm}$ compr., oblongas; ovário globoso, 0,5-0,7 mm diâm., glabro ou com tricomas glandular-estipitados, estilete 1,8-2,0 mm 
compr., tricomas até o 1/4 apical. Baga globosa, 4,0-7,0 mm diâm., não envolvida pelo cálice frutífero, inerme, glabro, epicarpo brilhante, negro, glabro; pedicelo frutífero deflexo, $8,0-10,0 \times 0,8-0,9 \mathrm{~mm}$, inerme, glabro; sementes numerosas, 1,2-1,5×1,3-1,5 mm, discóides a subreniformes, pardas.

De acordo com Edmonds (1977) e D'Arcy (1991), Solanum americanum é uma espécie encontrada em todos os países de clima tropical e temperados mais quentes, onde foi introduzida da América do Sul. No Brasil, encontra-se amplamente distribuída, desde as regiões mais frias do Sul (Mentz \& Oliveira 2004), até as mais quentes e secas do Nordeste. Na Paraíba, a espécie ocorre de forma ruderal, anual, habitando preferencialmente lugares úmidos e sombreados, em solos humosos, muitas vezes crescendo como invasora em campos cultivados ou em terrenos abandonados.

Material examinado: BRASIL. Paraíba: Alagoinha, Estação Experimental, 10/VII/1942, fl. fr., Xavier 887 (JPB); Antenor Navarro, Brejo das Freiras, 31/VII/1974, fl. fr., Xavier s.n. (JPB); Areia, 2/IV/1954, fl. fr., Moraes s.n. (JPB); X/1993, fl. fr., Agra \& Rocha 2111 (JPB); Cabaceiras, estrada para Boa Vista, 29-30/VI/1994, fl. fr., Agra et al. 3138 (JPB); Campina Grande, 2/VI/1989, fl. fr., Agra 90 (JPB); Riachão do Bacamarte, 16/VIII/1989, fl. fr., Agra 792 (JPB); João Pessoa, Praça da Independência, 26/IX/1942, fl. fr., Espínola s.n. (JPB); Cidade Universitária, 20/II/1990, fl. fr., Agra 1108 (JPB); Maturéia, 18/I/1997, fl. fr., Agra et al. 3892 (JPB); 10-15/V/1998, fl. fr., A gra et al. 5326 (JPB); 13-14/IV/2002, Agra et al. 5784 (JPB).

3. Solanum asperum Rich., Act. Soc. Hist. Nat. Par. 1: 107. 1792.

Fig. 9-11, 46

Arbusto ereto, 1,5-3,0 m alt., inerme; caule e ramos cilíndricos, pseudostipulas ausentes, ocráceo-tomentosos, tricomas porrecto-estrelados e multiangulados, sésseis e estipitados, decíduos. Folha simples, pecíolo séssil ou subséssil, 0,3-0,5 cm compr., lâmina 5,0-13,0×2,0-3,5 cm, cartácea, elíptica, aguda no ápice e na base, decurrente no pecíolo, face adaxial áspera, tricomas porrecto-estrelados, sésseis, decíduos, face abaxial tomentosa, tricomas porrecto-estrelados, sésseis e estipitados. Inflorescências em cimeiras dicotômicas, multifloras, pedúnculos $3,0-7,0 \mathrm{~cm}$ compr., pedicelos 4,0-5,0 mm compr., deflexos nas flores e eretos nos frutos, articulados na base, indumento com tricomas porrecto-estrelados e multiangulados, sésseis e subsésseis. Flores monoclinas, cálice campanulado, sépalas soldadas próximo do 1/2, tubo 2,0-2,5 mm compr., lobos ovallanceolados, 2,0-2,5 mm compr., externamente estreladotomentoso; corola estrelada, alva, 0,8-1,0 cm diâm., tubo 2,0-2,5 mm compr., lobos 3,5-4,0 mm compr., oblongolanceolados; filetes 0,8-1,0 mm compr., anteras 1,9-2,0 mm compr., oblongas; ovário globoso, 2,0-2,5 mm diam., hirsuto, estilete 5,0-7,0 $\mathrm{mm}$ compr., piloso até a $1 / 2$ basal. Baga globosa, $0,8-1,0 \mathrm{~cm}$ diâm., não envolvida pelo cálice frutífero, inerme, epicarpo verde-escuro, pubescente, tricomas porrecto-estrelados, decíduos; pedicelo frutífero ereto, 3,5-7,0 $\times 1,5-2,0 \mathrm{~mm}$, inerme, estrelado-pubescente; sementes numerosas, $1,0-1,5 \times 1,2-1,5 \mathrm{~mm}$, ovais, testas foveoladas, pardas.

De acordo com Roe (1972), Solanum asperum é uma espécie neotropical, com distribuição na América Central (Belize, Panamá e Trinidad) e América do Sul (Venezuela e Brasil), ocorrendo em vegetação secundária de florestas úmidas. No Brasil, a espécie foi registrada por Nee (1991) para os Estados de Amapá, Bahia, Ceará, Goiás, Maranhão, Mato Grosso, Rio de Janeiro e Roraima. Na Paraíba, é uma espécie somente encontrada em remanescentes de Floresta Atlântica, sempre associada à vegetação secundária, em altitudes de 0 a $550 \mathrm{~m}$. Espécie vulnerável no Estado, principalmente pela destruição de seu hábitat.

Material selecionado: BRASIL. Paraíba: Alagoinha, Estação Experimental, 10/VII/1942, fl. fr., Xavier s.n. (JPB); Areia, Fazenda Saboeiro, 9/IX/1974, Xavier s.n. (JPB); 12/VII/1976, fl., Fevereiro 128 (EAN, RB); próximo ao CCA, Campus da UFPB, 12/III/1996, fl. fr., A gra et al. 3508 (JPB); Cabedelo, Restinga de Camboinha, 28/XII/1969, fl. fr., Xavier s.n. (JPB); Cruz do Espírito Santo, Engenho São Paulo, 1/I/1969, fl. fr., Xavier s.n. (JPB); Guarabira, 7/IX/1942, fl., Espínola s.n. (JPB); João Pessoa, Granja Santa Fé, 9/XI/1971, fl., Carvalheira s.n. (JPB); Mata do Buraquinho, 5/II/1974, fl., Correia s.n. (JPB); Campus UFPB, próximo ao LTF, 12/VII/1984, fl. fr., Agra 521 (JPB, RB); CCHLA, 20/10/2006, fl., Agra \& Nurit 6760 (JPB); Pedras de Fogo, 9/VII/1986, fl., Agra 530 (JPB); 30/III/1988, fl., Agra 645 (JPB, RB); Rio Tinto, Aldeia do Jacaré, 23/II/1989, fl. fr., Agra et al. 685 (JPB, RB); Santa Rita, 24/IV/1987, fl. fr., Agra 559 (JPB); 16/VI/2001, fl. fr., Agra et al. 5614 (JPB).

4. Solanum asterophorum Mart., Flora 21, Beibl. 2: 79. 1838. Fig. 46

Arbusto ereto, 1,0-2,0 m alt., aculeado; caule e ramos cilíndricos, tomentosos, marrons a enegrescidos, tricomas porrecto-estrelados, sésseis, acúleos aciculares, 2,0-5,0 mm compr., ferrugíneos a marrons. Folhas geminadas, pecíolo 1,0-6,5 cm compr., sulcado, acúleos 1,0-5,0 mm compr. ou ausentes, lâmina 6,0-17,5×3,5-10,0 cm, cartácea, elíptica ou oval-elíptica, aguda no ápice, cuneada ou oblíqua na base, inteira ou 4-5-lobada, face adaxial escabra a tomentosa, castanho escuro a nigrescente, tricomas porrecto-estrelados, face abaxial tomentosa a velutina, tricomas estrelados, estipitados. Inflorescência em cimeira, 2-5-flora, pedúnculo 0,2-0,6 cm compr., pedicelo 1,5-1,8 cm compr., inerme. Flores monoclinas e estaminadas, cálice campanulado-urceolado, tomentoso, tubo 4,0-5,0 mm compr., lobos 2,0-3,0×1,5-2,0 mm, lineares a triangulares, corola rotáceo-estrelada, alva, 2,5-3,0 cm diâm., tubo 4,0-5,0 mm compr., lobos 1,0-1,3 cm compr., oblongo-elípticos, externamente estreladopubescentes, filetes $1,0-1,5 \mathrm{~mm}$, anteras 7,0-7,5 $\mathrm{mm}$ compr., lanceoladas, ovário oval a subcônico, 1,0-1,5 mm compr., tomentoso, estilete 1,0-1,3 cm compr. nas flores monoclinas, 0,3-0,5 cm compr. nas estaminadas, estrelado-pubescente. 
Baga subglobosa, 1,5-2,0 cm diâm., cálice frutífero acrescente, subinerme a aculeado, epicarpo verde a marron, glabro; pedicelo frutífero deflexo, 18,0-25,0×1,5-2,5 mm, inerme, tomentoso; sementes numerosas, 3,0-3,5×2,5-3,0 mm, subreniformes a reniformes, pardas.

Exclusiva da flora brasileira, S. asterophorum possui distribuição em Alagoas, Bahia, Espírito Santo, Minas Gerais, Paraíba, Pernambuco, Rio de Janeiro e Sergipe (Agra 2007), sempre associada a ambientes úmidos, principalmente em Floresta Atlântica. Na Paraíba, é uma espécie rara, somente coletada em duas áreas, em altitudes acima de $500 \mathrm{~m}$. Bastante vulnerável, pois sua ocorrência não foi registrada em áreas protegidas.

Material examinado: BRASIL. Paraíba: Areia, 17/X/1988, fl., Felix \& Dornelas 1411 (EAN, JPB); 31/VII/1992, Agra \& Silva 1763 (JPB); 12/X/1992, fl., Agra \& Bhattacharyya 1744 (JPB); 12/X/1992, fl., Agra \& Bhattacharyya 1745 (JPB); 12/III/1996, fl., A gra et al. 3533 (JPB); 12/III/1996, fr., A gra et al. 3534 (JPB); 12/III/1996, fl. fr., Agra et al. 3511 (JPB); 12/VIII/2008, est., Agra et al. 7010 (JPB); Fagundes, Pedra de Santo Antônio, 5/IX/2006, est., Agra et al. 6848 (JPB).

Material adicional examinado: BRASIL. Alagoas: Pilar, Faz. Lamarão, 16/VII/1998, fl., Lyra-Lemos 3889 (MAC).

\section{Solanum caavurana Vell., Fl. flum. 2: 86. 1825.}

Fig. 12-15, 46

Arbusto ereto, 2,0-3,0 m alt., inerme; caule e ramos cilíndricos, glabros, lúcidos. Folhas alternas, geminadas, glabras, dimorfas, pecíolo 0,6-1,2 cm compr., lâmina 5,0-13× 2,5-4,0 cm, membranácea a cartácea, elíptica a oval-elíptica, ápice agudo a acuminado, base atenuada, margem inteira, ambas as faces glabras, face abaxial com tufos de tricomas simples, eglandulares, raro glandulares, nas axilas da nervura principal. Inflorescência em cimeira helicoide, 5-20-flora, pedúnculo 1,5-2,0 cm compr., pedicelo 1,0-1,5 cm compr., articulado, glabro, 5-costado na porção distal. Flores monoclinas, cálice campanulado, tubo 4,5-5,0 mm compr., lobos 3,0-3,5 mm compr., oval-oblongos a oblongos, dorsalmente espessados na base; corola estrelada, alva, 1,5-2,0 cm diâm., tubo 2,0-3,0 mm compr., lobos 8,0-10,0× 2,0-3,0 mm, triangular-lanceolados a elípticos, agudos no ápice; filetes 1,0-1,5 mm compr. da porção livre, anteras 4,0-4,5 mm compr., obelípticas; ovário oboval, 1,5-2,0 mm diâm., glabro, estilete 0,8-1,0 cm compr., cilíndrico. Baga subglobosa, 1,5-2,0 cm diâm., cálice frutífero não acrescente, inerme, epicarpo verde-amarelado, lúcido, glabro; pedicelo frutífero levemente deflexo, 20,0-25,0×1,5-2,2 mm, inerme, glabro; sementes numerosas, 2,5-3,0×1,8-2,0 mm, reniformes, aladas, beges.

Espécie exclusiva da América do Sul, com distribuição no Brasil, Paraguai e Argentina. É encontrada em florestas úmidas, frequentemente de crescimento secundário, em altitudes de 0 a $250 \mathrm{~m}$ (Knapp 2002). No Brasil, foi coletada desde o Ceará até São Paulo. Na Paraíba, Solanum caavurana é conhecida de poucas coletas em ambientes úmidos de Floresta Atlântica. Apesar da maior parte de sua área de ocorrência ser também a de expansão dos canaviais no Estado, a espécie também foi registrada na Reserva Estadual da Mata do Pau Ferro, Paraíba, e no Jardim Botânico de João Pessoa.

Material examinado: BRASIL. Paraíba: Areia, Mata do Pau-Ferro, 13/III/2001, fl., Belém et al. 07 (EAN); Caaporã, 21/VI/1988, fr., Miranda \& Medeiros s.n. (JPB 158791); Conde, 28/III/1996, fl. fr., Agra \& Góes 3692 (JPB); João Pessoa, Varjão, 30/V/1978, fl. fr., Agra 014 (JPB); Marés, 9/VIII/1990, fl., Agra 1249 (JPB); 9/XI/2005, fl. fr., A gra et al. 6492 (JPB); Mata do Buraquinho, Jardim Botanico, 21/VIII/2008, fl., A gra et al. 7032 (JPB, NY, UT) Pedras de Fogo, 30/III/1988, fl., Agra 646 (JPB); Remígio, 26/IV/2001, fl. fr., Grisi 180 (JPB); Santa Rita, 8/III/1996, fl. fr., Agra \& Góes 3685 (JPB).

6. Solanum capsicoides All., Auct. Syn. Meth. Stirp. Hort. Reg. Taurensis 64. 1773.

Fig. 16-20, 46

Arbusto, ereto ou ascendente, 0,3-0,7 m alt., fortemente aculeado; caule e ramos cilíndricos, flexuosos, pilosos, tricomas glandulares e eglandulares, unisseriados, acúleos aciculares, 1,0-1,5 cm compr. Folhas geminadas, acúleos 1,5-2,0 cm compr., pecíolo 2,0-6,0 cm compr., cilíndrico, lâmina 7,0-15,0×5,5-12,0 cm, cartácea, 2-3 pares de lobos, agudos ou arredondados, ápice agudo, base cordada, acúleos acompanhando a venação, pilosa, tricomas simples, glandular-estipados e eglandulares, unisseriados, hialinos, maiores e mais esparsos na face abaxial, margem ciliada. Inflorescência subséssil 4-6-flora, pedicelo ca. 1,0 cm, articulado, acúleos 4,0-5,0 mm compr., aciculares. Flores monoclinas e estaminadas, cálice campanulado, 3,8-4,0 mm compr., lobos 1,0-2,0 mm compr., triangulares, tricomas semelhantes aos dos ramos; corola estrelada, alva, tubo 1,0-1,5 mm, lobos 1,2-1,4×0,2-0,4 cm, triangular-lanceolados; filetes 1,5-2,0 $\mathrm{mm}$ compr., anteras $6,0-7,0 \mathrm{~mm}$ compr., lanceoladas; ovário globoso, 1,5-2,0 mm diâm., tricomas glandular-estipitados, esparsos, estilete 8,0-9,0 mm compr., reduzidos nas flores estaminadas. Baga globosa, 2,5-3,0 cm diâm., não envolvida pelo cálice acrescente, aculeado, epicarpo variegado a vermelho-laranja no fruto maduro, glabro; pedicelo frutífero deflexo, 20,0-25,0×1,5-2,5 mm, aculeado, pubescente; sementes numerosas, 3,0-4,0× 3,0-3,5 mm, suborbiculares, aladas, pardas.

Espécie neotropical com ampla distribuição, encontrada desde os Estados Unidos, Costa Rica, Bermuda, Haiti, Ilhas do Caribe, República Dominicana, Martinica, Colômbia, Venezuela, Peru e Brasil. Foi registrada para os estados da Bahia, Distrito Federal, Minas Gerais, Paraíba, Pernambuco, Rio de Janeiro, Santa Catarina, São Paulo (Agra 2007). Na Paraíba, a maioria dos espécimes foi coletada em áreas do litoral, em solos arenosos e areno-argilosos. Apenas duas coletas foram registradas para uma área extra-litorânea (Agra 74, Agra et al. 2258).

Material selecionado: BRASIL. Paraíba: Campina Grande, 30/VI/1989, fr., Agra 745 (JPB); 10-12/IX/1993, fl., 
Agra et al. 2258 (JPB); Conde, 23/VIII/2004, fl. fr., Agra \& Sarmento 6312 (JPB); João Pessoa, 19/XII/1971, fl. fr., Correia 3971 (JPB); 26/VI/1973, fr., Carvalheira 3532 (JPB); 5/VII/1978, fl. fr., Agra 44 (JPB); 1/X/1988, fr., Agra 662 (JPB); 9/VIII/1990, fr., Agra 1267 (JPB); 22/XI/1991, fr., Agra \& Bhattacharyya 1329 (JPB); 29/IV/1992, fr., Agra 1524 (JPB); 21/XI/1993, fl. fr., Agra \& Bhatacharyya 2403 (JPB); 17/III/1994, fr., Agra 2817 (JPB); Mata Redonda, 30/III/1988, fl, fr., Agra 648 (JPB, RB); Rio Tinto, 23/II/1989, fl. fr., Agra et. al. 684 (JPB, RB); Santa Rita, 15/VII/1989, fl. fr., Agra 1119 (JPB).

\section{Solanum crinitum Lam., Tabl. Encycl. 2: 20. 1794.}

Fig. 46

Arbusto a arvoreta, 2,0-3,0 m alt., aculeado; caule e ramos cilíndricos, velutinos, vilosos ou crinitos, tricomas estrelados longo-estipitados, cerdosos, 0,5-1,3 cm compr., filiformes, acúleos aciculares a cônicos, 1,0-2,5 cm compr. Folhas solitárias, pecíolo 2,0-5,0(15,0) cm compr., quadrangular-complanado, lâmina 8,0-20,0(-40,0)× $5,5-15,0(-43,0) \mathrm{cm}$, subcoriácea a coriácea, oval-elíptica ou lobado-angulada, ápice agudo, base cordiforme ou oblíqua, discolor, face adaxial rugosa, tomentoso-escabra ou velutina, inerme ou com acúleos aciculares, 0,5-1,5 cm compr., face abaxial denso-vilosa, acúleos aciculares na nervura principal. Inflorescência em cimeira 5-15-flora, acúleos esparsos, pedúnculo 1,0-2,5 cm compr., pedicelo 0,6-1,5 cm compr., articulado, indumento de tricomas estreladoestipitados e cerdoso. Flores monoclinas e estaminadas, cálice oval-oblongo, tubo 0,3-0,5 cm compr., lobos 1,0-1,5 cm compr., oblongo-lineares; corola pentagonal-estrelada, lilás ou púrpura, 4,0-6,0-(7,0) cm diâm., levemente zigomorfa, plicada, lobos 1,0-2,5-(4,0) cm compr.; filetes 2,0-3,0 mm compr., anteras 1,8-2,2 cm compr., lineares ou subuladas, tricomas estrelados, alvos; ovário subgloboso, 2,3-2,5 mm diâm., hirsuto, estilete 2,0-2,5 cm compr., 0,4-0,6 mm compr. nas flores estaminadas. Baga globosa, 4,0-8,0 cm diâm., não envolvida pelo cálice acrescente, inerme a subinerme, epicarpo verde-canescente, velutino a tomentoso; pedicelo frutífero deflexo, 20,0-30,0×3,0-5,0 mm, fortemente aculeado, tomentoso a velutino; sementes numerosas, 3,0-3,2× 3,0-3,3 mm, suborbiculares a ovóides, foveoladas, negras.

Exclusiva da América do Sul, com distribuição na Venezuela, Colômbia, Equador, Peru, Guiana, Guiana Francesa, Suriname, Brasil e Bolívia. Solanum crinitum possui distribuição ampla no Brasil, encontrada no Norte, Nordeste e Sudeste do país, em áreas de semi-árido, cerrado, restingas e campos rupestres (Agra 2007). Espécie rara e bastante ameaçada na Paraíba, sua ocorrência é conhecida de apenas uma localidade, em área de praia, com grande expansão imobiliária.

Material examinado: BRASIL. Paraíba: Conde, 24/IX/1998, fl. fr., Moura 175 (JPB); Praia de Jacumã, 23/VIII/2004, fl. fr., Agra \& Sarmento 6313 (JPB); fl. fr., Agra \& Sarmento 6314 (JPB); 27/IV/2006, fl. fr., A gra et al. 6744 (JPB); 27/IV/2006, est., A gra et al. 6753 (JPB); 20/VIII/2008,

\section{fl. fr., Agra et al. 7028 (JPB, NY, UT).}

8. Solanum jabrense Agra \& M. Nee, Brittonia 49(3): 350-353. 1997.

Fig. 46

Arbusto a arvoreta, ereto ou subescandente, 1,5-3,0 m alt., aculeado; caule e ramos cilíndricos, glabros ou tomentosos, tricomas estrelados sésseis, acúleos aciculares 2,0-5,0 mm. Folhas solitárias, pecíolo 2,0-4,0 cm compr., ferrugíneo-tomentoso, lâmina 4,0-12,0×2,5-8,0 cm, cartácea, oval, oval-lanceolada ou oval-cordiforme, inteira ou lobadoangulada, ápice agudo ou acuminado, base assimétrica ou cordiforme, acúleos 0,3-0,8 cm compr., acompanhando a venação principal, face adaxial tomentoso-escabra, ferrugínea, tricomas estrelados sésseis, face abaxial velutina, amarelada, tricomas multiangulados estipitados. Inflorescência em cimeira escorpióide, 5-10-flora, pedúnculo 2,0-4,0 cm compr., pedicelo 8,0-9,0×1,0-1,5 mm, articulado. Flores monoclinas e estaminadas, cálice campanulado, tubo 2,0-3,0 mm compr., lobos 4,0-6,0×1,5-2,0 mm, linearlanceolados, recurvos; corola estrelada, lilás a violácea, 2,5-3,0 cm diâm., tubo 0,3-0,5 cm compr., lobos 1,2-1,5× 0,3-0,5 cm, linear-lanceolados; filetes $2,0 \mathrm{~mm}$ compr., anteras 1,0-1,1 cm compr., linear-lanceoladas; ovário subgloboso, 1,5-2,0 mm diâm., hirsuto, estilete glabro, 1,0-1,2 cm compr., 0,4-0,5 cm nas flores estaminadas. Baga subglobosa, 1,0-1,5 cm diâm., não envolvida pelo cálice acrescente, inerme, epicarpo verde a amarelo-laranja, glandulosoviscoso, pedicelo frutífero deflexo, 6,0-7,0×1,5-2,0 mm, aculeado, estrelado-glanduloso; sementes numerosas, 2,0-3,0×2,1-2,9 mm, suborbiculares a reniformes, beges a marron-claras.

Espécie exclusiva da flora brasileira, com distribuição restrita aos brejos de altitudes da região Nordeste, em elevações acima de 600 m, na Bahia, Ceará, Paraíba e Pernambuco (Agra 2004). Na Paraíba, a espécie foi coletada em altitudes que variam de 700 a $1.100 \mathrm{~m}$, associada a ambientes rochosos, constituídos por blocos graníticos e gnáissicos. Trata-se de uma espécie pouco comum, entretanto, sua ocorrência foi registrada na Unidade de Conservação Estadual do Pico do Jabre e na RPPN Fazenda Almas.

Material selecionado: BRASIL. Paraíba: Maturéia, Serra de Teixeira, 2-3/IV/1991, fl. fr., Agra \& Barbosa 2820 (JPB, NY, MO); 16/III/1993, fl., Agra et al. 1928, 1998 (JPB, NY); 27/II/1994, fl. fr., Agra et al. 2648 (JPB); 27/III/1994, fl., Agra et al. 2580 (IPA, JPB, NY); 16/VI/1995, fl. fr., Figueiredo 88 (JPB); 18/I/1997, fl. fr., A gra et al. 3904 (JPB); 18/I/1997, fl. fr., Agra et al. 3918. (JPB); 23/XII/1997, fl., Agra et al. 4360 (JPB); 10/II/1998, fl. fr., Agra et al. 4980 (JPB, MO); 23/IV/1998, fl., Agra et al. 5257 (JPB, RB); 12/II/2000, Agra \& Sarmento 5549 (JPB); 13/VIII/2008, fl. fr., A gra et al. 7016 (JPB, NY, UT); Monteiro, Serra de Jabitacá, 27/IV/2006, fl. fr., Gadelha-Neto \& Pontes 1518 (JPB); São José dos Cordeiros, RPPN Faz. Almas, 23/III/2003, fl. fr., Lima et al. 82 (JPB); Serra Branca, 8-11/III/2002, fl. fr., A gra et al. 5713 (JPB). 


\section{Solanum melissarum Bohs, Taxon 44(4): 584. 1995.} Fig. 46

Arvoreta, 2,0-3,0 $\mathrm{m}$ alt., inerme; caule e ramos cilíndricos, lenticelados, glabros. Folhas simples, solitárias, raro geminadas, pilosas, tricomas simples, eglandulares, unisseriados, pecíolo 1,5-2,5 cm compr., cilíndrico, sulcado. lâmina 5,5-12,0×3,5-4,5 cm, cartácea, elíptica oval-elíptica, ápice acuminado base cuneada, oblíqua ou arredondada, margem inteira, ciliada. Inflorescências em cimeiras simples, 8-25-flora, pedúnculo 2,0-4,0 cm compr., sulcado, pedicelo 1,0-1,5 cm compr., articulado na base, indumento semelhante ao das folhas. Flores monoclinas, cálice campanulado, pubescente, tubo 1,0-1,5 mm compr., lobos 2,5-3,0 mm compr., triangulares, agudos, corola estrelado-campanulada, alvoesverdeada, tubo 2,0-3,0 mm compr., lobos 0,8-1,0×0,3-0,4 cm, triangulares, anteras lanceoladas, 7,0-7,5 $\times 1,5-2,0 \mathrm{~mm}$, conectivo ampliado na base, arroxeado; ovário obovóide, 1,5-2,0 mm diâm., glabro, estilete 8,0-8,5 mm compr., estigma dilatado distalmente, truncado. Botão floral estreito-ovóide, agudo, pubescente. Baga oblongo-elíptica, 3,5-4,0× 2,0-3,0 cm, não envolvida pelo cálice acrescente, inerme, epicarpo verde a amarelado, glabro; pedicelo frutífero 20,0-30,0×1,5-2,5 mm, inerme, glabro; sementes numerosas, $3,0-4,0 \times 1,5-3,0 \mathrm{~mm}$, reticuladas, pardas.

Espécie exclusiva da flora brasileira, encontrada na Paraíba, Bahia, Minas Gerais, Rio de Janeiro, Santa Catarina e São Paulo (Bohs 1994). Foi transferida de Cyphomandra (C. divaricata (Mart.) Sendtn.) para Solanum por Bohs (1995). Na Paraíba, a espécie era conhecida de apenas duas coleções, ambas realizadas em uma área de Brejo de Altitude, em elevações de 550-600 m, no ano de 1953. A espécie foi recentemente coletada (Agra et al. 7039) na mesma localidade já citada para o Estado.

Material examinado: BRASIL. Paraíba: Areia, em lugares altos, 23/V/1953, fl. fr., Moraes 735 (EAN, JPB); 4/VI/1953, fr., Moraes s.n. (EAN, RB 85225); 12/VIII/2008, est., Agra et al. 7039 (JPB)

10. Solanum ovum-fringillae (Dunal) Bohs, Taxon 44(4): 585. 1995.

Fig. 46

Arvoreta, 2,5-3,0 m alt., inerme; caule e ramos cilíndricos, carnosos, pubérulos e pilosos, tricomas simples, esparsos, pluricelulares, unisseriados. Folhas simples ou compostas, decíduas quando secas, pecíolo 0,4-1,5(-2,7) compr., pubérulo-piloso, lâmina 3,5-6,0×2,0-3,0 cm, cartácea, cordiforme, oval-eliptica ou oval-cordiforme, ápice acuminado, base oblíqua ou cordiforme, margem inteira, ciliada. Inflorescência em cimeira simples, escorpióide, 5-25-flora, pedúnculo 1,0-2,0 cm compr., pedicelo 4,0-7,0 mm compr., articulado próximo da base. Flores monoclinas, pêndulas, cálice urceolado-radiado, crasso, membranáceo puberulento, tricomas simples, sépalas soldadas no $1 / 4$ basal, tubo 1,0-2,0 mm, lobos 2,0-2,5×1,2-1,5 mm, triangular-elípticos; corola estrelada, lilás ou púrpura, tubo 1,0-1,5 mm compr., lobos ca. 1,0 cm compr., triangulares, pubérulos, crassos; filetes $0,8-1,0 \mathrm{~mm}$ compr., laminares, anteras 5,5-6,0× 1,5-2,0 mm, oval-elípticas a elípticas, roxas, conectivo espessado, avermelhado, 3,5-4,5×1,0-2,0 mm; ovário ovóide, 2,2-2,5 mm diâm., glabro, estilete 6,5-7,0 mm compr., estigma capitado, truncado. Baga ovóide, 1,5-2,0×0,6-1,0 cm, não envolvida pelo cálice acrescente, inerme, epicarpo verde a amarelo-claro, glabro; pedicelo frutífero deflexo, 15,0-20,0× 2,0-2,2 mm, inerme, glabrescente, tricomas simples; sementes numerosas, 1,5-2,0×1,4-2,0 mm, ovóides, pardas.

Solanum ovum-fringillae, transferida por Bohs (1995) de Cyphomandra (C. ovum-fringillae Dunal) para Solanum, é uma espécie rara exclusiva da flora brasileira. De acordo com Bohs (1994), a espécie era conhecida de apenas duas coleções, uma do tipo, coletado na Bahia, e outra de Pernambuco. Sua ocorrência na Paraíba está sendo aqui referida pela primeira vez, encontrada em duas áreas de mata serrana, sendo uma na Unidade de Conservação do Pico do Jabre, em altitudes de 600-1.000 m.

Material examinado: BRASIL. Paraíba: Maturéia, Serra de Teixeira, 12/VII/1997, Agra et al. 4096 (JPB); 20-23/XII/1997, fl., A gra et al. 4382 (JPB); 7-10/II/1998, fl. fr., Agra et al. 5053 (JPB, RB); 23/IV/1998, fr., Agra \& Silva 5218 (JPB); São José da Mata, 31/VII/2004, fr., GadelhaNeto et al. 1241 (JPB).

11. Solanum palinacanthum Dunal, DC. Prodr. 13(1): 245. 1852. Fig. 21-26, 47

Arbusto ereto, 0,5-1,0 m alt., fortemente aculeado; caule e ramos cilíndricos, glanduloso-puberulentos, tricomas glandulares, eglandulares e estrelados, esparsos, acúleos aciculares, 0,2-1,6 cm. Folhas isoladas, pecíolo 3,0-6,5 cm compr., acúleos aciculares, 1,5-2,0 cm compr., lâmina 4,0-12× 8,0-12,0 cm, cartácea, oval-lanceolada ou oval-cordiforme, ápice agudo ou obtuso, base cordada, 4-6 pares de lobos, acúleos 0,5-1,5 cm compr., face adaxial com tricomas unisseriados, hialinos, glandular-estipitados, e estrelados, esparsos, face abaxial estrelado-pilosa. Inflorescência em cimeira simples, subsésseis, 6-10-flora, pedúnculo 2,0-4,0 mm compr., pedicelo 0,8-1,0 cm compr., articulado, acúleos aciculares, 1,0-2,0 mm. Flores monoclinas e estaminadas, cálice tubuloso-campanulado, sépalas soldadas até próximo do 1/4 apical, tubo 2,0-2,5 mm compr., lobos 2,5-3,0 mm, deltóides; corola estrelada, violeta ou púrpura, pétalas soldadas no $1 / 4$ basal, lobos 1,2-1,5×0,3-0,4 cm, linearlanceolados; filetes 1,0-1,5 mm compr., anteras lanceoladas, 1,6-1,7 cm compr.; ovário globoso, 2,0-2,5 mm diâm., estilete $1,0-1,2 \mathrm{~cm}$ compr. nas flores monoclinas, $0,4-0,5 \mathrm{~cm}$ nas estaminadas. Baga globosa a subglobosa, 3,0-3,5 cm diam., não envolvida pelo cálice acrescente, aculeado, epicarpo fosco, verde-variegado a amarelo-claro, glabro; pedicelo frutífero reflexo, 15,0-20,0×2,0-3,0 mm, aculeado, glandulosopubescente; sementes numerosas, 3,0-4,0×3,0-3,9 mm, lentiformes, subreniformes, beges.

Espécie exclusiva da América do Sul, com distribuição no Brasil, Bolívia, Paraguai e Argentina, em altitudes abaixo 

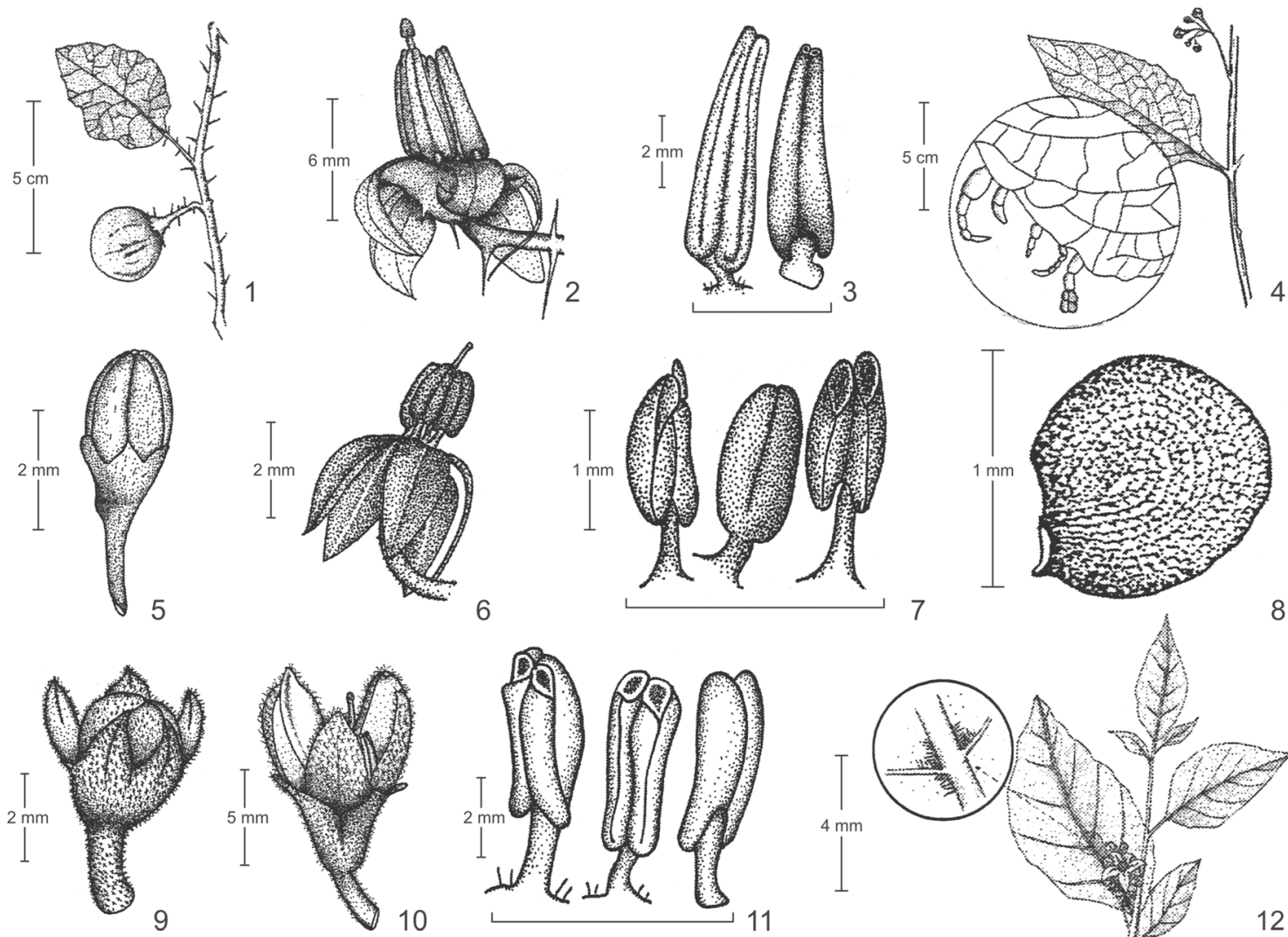

8
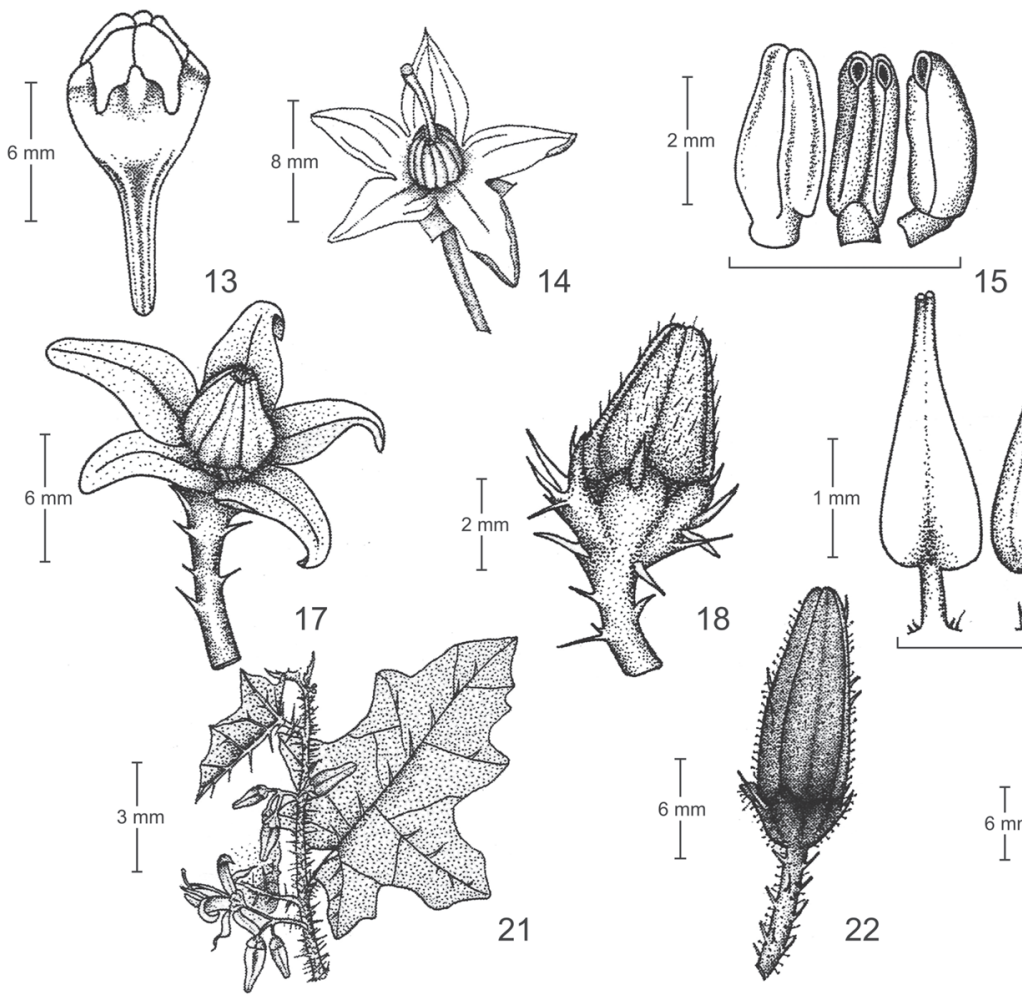

21
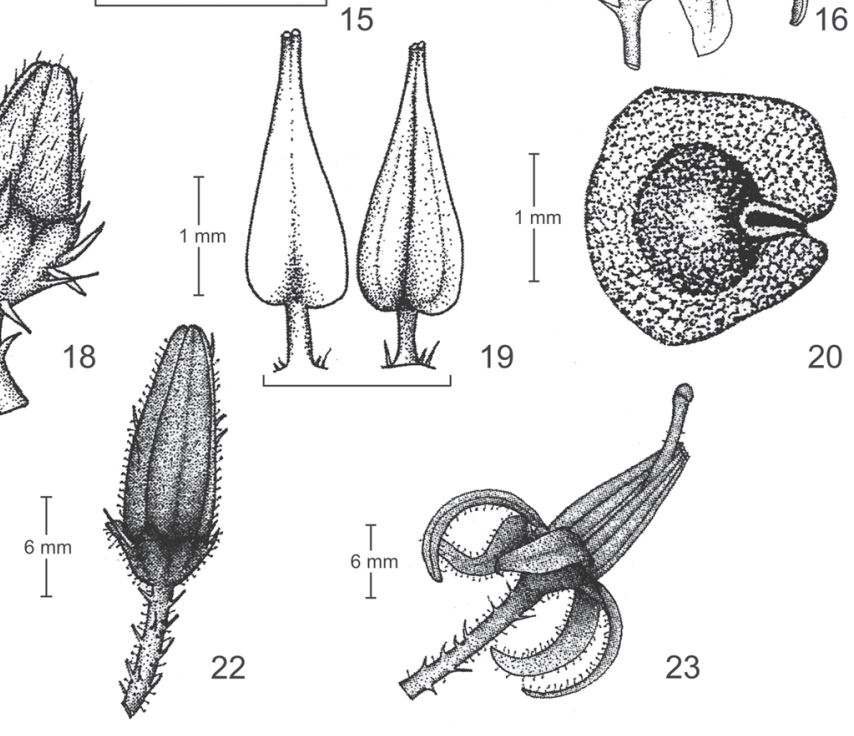

Figuras 1-3. Solanum agrarium Sendtn. (Agra 6249). 1. Detalhe do ramo com fruto. 2. Flor isolada. 3. Estame, em vista frontal e dorsal. 4-11. Solanum americanum Mill. (Agra 1108). 4. Ramo frutificado e detalhe ampliado dos tricomas da folha. 5. Botão floral. 6. Flor isolada. 7. Estame, vista de perfil, dorsal e frontal. 8. Semente. 9-11. Solanum asperum Rich. (Agra et al. 521). 9. Botão floral. 10. flor isolada. 11. Estame, de perfil, vista frontal e dorsal. 12-15. Solanum caavurana Vell. (Agra 1249). 12. Ramo florido e detalhe da nervura da face abaxial. 13. Botão floral. 14. Flor isolada. 15. Estame, vista frontal, dorsal e perfil. 16-20. Solanum capsicoides All. (Agra 1119). 16. Flor monoclina. 17. Flor estaminada. 18. Botão floral. 19. Estame,vista dorsal e frontal. 20. Semente. 21-23. Solanum palinacanthum Dunal (Agra 643). 21. Ramo florido. 22. Botão floral. 23. Flor isolada. 
de 1.200 m (Nee 1991). Possui distribuição ampla no Brasil, ocorrendo desde o norte até o sul do país. Na Paraíba, é uma espécie ocasional encontrada principalmente no litoral e de apenas duas coletas na caatinga (Miranda \& Moura 40 e Agra \& Sarmento 5550).

Material selecionado: BRASIL. Paraíba: Cajazeiras, 11/V/1982, fl., Miranda \& Moura 40 (JPB); João Pessoa, 30/III/1988, fl. fr., Agra 643 (JPB, RB); VII/1988, fl. fr., Agra 734 (JPB); 15/VII/1989, fl. fr., Agra \& Bhattacharyya 791 (JPB); 9/VIII/1990, fl. fr., A gra 1250 (JPB); 22/XI/1991, fl., Agra \& Bhattacharyya 1330 (JPB); 12/VIII/1993, fl., Agra \& Góis 2114 (JPB); Vieirópolis, 15/I/2000, fl. fr., Agra \& Sarmento 5550 (JPB).

12. Solanum paludosum Moric., Pl. Nouv. Amer. 29, pl. 20. 1837.

Fig. 27-29, 47

Arbusto a arvoreta, ereto, 1,5-4,0 m alt., aculeado; caule e ramos cilíndricos, tomentosos, tricomas glandularestrelados, sésseis, acúleos deltóides, 0,5-1,0 cm compr., ferrugíneos. Folhas simples, solitárias, pecíolo 2,0-4,0 mm, com ou sem acúleos, lâmina 7,0-12,0×4,0-8,0 cm, cartácea, oval ou oval-elíptica, ápice agudo, base obtusa, 3-4 pares de lobos agudos, face adaxial com tricomas glandular-estrelados, sésseis, face abaxial com tricomas glandularestrelados, estipitados, subinerme ou com acúleos subulados, $0,8-1,0 \mathrm{~cm}$. Inflorescência em cimeira simples, 5-15-flora, pedúnculo 2,5-3,0 cm compr., pedicelo 1,0-1,5 cm. Flores monoclinas e estaminadas, cálice oblongo-urceolado, ferrugíneo-tomentoso, tubo 4,0-5,0 mm compr., lobos 7,0-8,0×2,5-3 mm, triangular-lanceolados; corola estrelada, violácea ou púrpura, 3,5-4,0 cm diâm., tubo 1,0-2,0 mm compr., lobos 2,5-3,0×0,3-0,5 cm, linear-lanceolados; filetes 1,0-2,0 mm compr., anteras 1,2-1,5 cm compr., linearlanceoladas; ovário subgloboso, ca. 2,0 mm, hirsuto, estilete piloso no $1 / 4$ basal, 1,8-2,0 cm compr. nas flores monoclinas, 4,0-5,0 mm nas estaminadas. Baga globosa, 1,4-1,5 cm diâm., não envolvida pelo cálice acrescente, aculeado, epicarpo brilhante, verde-variegado a marrom-ferrugíneo, víscidopubescente; pedicelo frutífero ascendente, 10,0-15,0× 1,5-2 $\mathrm{mm}$, inerme, ferrugíneo-tomentoso; sementes numerosas, 2,4-2,5×2,0-2,2 mm, subreniformes, pardas.

Espécie exclusiva da América do Sul, encontrada na Venezuela, Guiana, Suriname, Guiana Francesa e Brasil, onde é encontrada desde o Estado do Amazonas até o Rio de Janeiro (Agra 2001), em áreas costeiras, clareiras de matas, restingas e tabuleiros, em solos arenosos, argilo-arenosos e salinos (Agra 2001; 2004). Na Paraíba, é uma espécie bastante comum em áreas de restingas e tabuleiros, mas também foi encontrada em uma área de Brejo de Altitude, em elevações que variam do nível do mar até $600 \mathrm{~m}$ de altitude.

Material selecionado: BRASIL. Paraíba: Areia, 12/III/1996, fl., A gra et al. 3510 (JPB); Cabedelo, 2/II/1969, fl., Xavier 2113 (JPB); 15/IX/1974, fl., Xavier 3649 (JPB); 3/XII/1985, fl., Xavier 3398 (JPB); 23/IX/1996, fl. fr., Silva
13 (JPB); João Pessoa, 4/IX/1941, fl. fr., Xavier 256 (JPB); 12/XI/1966, fl. fr., Alves 2943 (JPB); 9/VIII/1969, fl., Xavier 2801 (JPB); 18/X/1971, fl., Correia 47 (JPB); 4/VII/1978, fl. fr., Agra 31 (JPB); 18/I/1981, fl., Xavier 5549 (JPB); 10/XII/1989, fl. fr., A gra 1100 (JPB); 20/II/1990, fl. fr., Agra 1107 (JPB); 3/XII/1992, fl., Neto 3 (JPB); 22/IX/1994, fl., Agra 3166 (JPB); 1/X/1995, fl., Neto 258 (JPB); 23/X/1997, fl. fr., Schlindwein 833 (JPB); Mamanguape, 30/VIII/1989, fl., Félix 2118 (JPB); 6/III/1990, fr., Félix 2784 (JPB); Pedras de Fogo, 30/III/1988, fl. fr., A gra 644 (JPB); Santa Rita, prox. Rio Miriri, 23/II/1987, fl. fr., Agra \& Góis 703 (JPB, RB); XI/1994, fl., Agra \& Góis 3616 (JPB).

\section{Solanum paniculatum L., Sp. pl. (ed. 2) 1:267. 1762.} Fig. 47

Arbusto ereto, 1,5-2,5 m alt., aculeado; caule e ramos cilíndricos, tomentosos a velutino, canescentes, tricomas porrecto-estrelados, sésseis e estipitados, acúleos cônicos, 0,5-1,0 cm. Folhas solitárias, tomentosas a vilosas, subinermes ou aculeadas, pecíolo 2,5-4,0(-10,0) cm compr., cilíndrico, lâmina 5,0-25×3,5-9,5(-25) cm, cartácea a subcoriácea, largo-oval, deltóide ou lanceolada, inteira ou repanda, ápice agudo a acuminado, base oblíqua, obtusa ou cordada, face adaxial laxo-tomentosa, tricomas estrelados sésseis, esparsos, face abaxial canescente, tomentosa a vilosa, tricomas estrelados, estipitados. Inflorescência 20-pluriflora, ramificada, pedúnculo 1,0-3,0 cm compr., pedicelo $0,7-1,5 \mathrm{~cm}$. Flores monoclinas e estaminadas, cálice campanulado, sépalas soldadas na base, tubo 2,0-2,5 mm compr., lobos 1,5-2,5 mm compr., triangular-acuminados; corola rotáceo-estrelada, plicada, cerúlea, lilás ou alva, pétalas soldadas na base, tubo 2,0-3-0 mm compr., lobos 5,0-1,2 cm compr., triangular-lanceolados; filetes 1,8-2,0 mm compr., anteras 0,8-1,0 cm compr., linear-lanceoladas; ovário subgloboso, 1,5-1,8 mm diâm., piloso no 1/4 apical, estilete estrelado-piloso na base, 1,0-1,2 cm nas flores monoclinas, 0,4-0,5 cm nas estaminadas. Baga globosa, 1,5-1,7 cm diâm., não envolvida pelo cálice acrescente, inerme, epicarpo brilhante, verde a marrom, glabro; pedicelo frutífero deflexo, $15,0-22,0 \times 2,0-2,5 \mathrm{~mm}$, inerme, tomentoso; sementes numerosas, 3,0-3,2×2,2-2,5 $\mathrm{mm}$ subreniformes, beges, foveoladas.

Exclusiva da América do Sul, Solanum paniculatum é encontrada no Brasil, Paraguai e Argentina (Nee 1999). No Brasil, a espécie possui ampla distribuição, ocorrendo em todas as regiões do país. É uma espécie muito comum na Paraíba, ocorrendo desde o litoral até a caatinga, em terrenos baldios ou abandonados e às margens de estradas, sem grande exigência quanto ao tipo de solo, em altitudes de $0-1.000 \mathrm{~m}$.

Material selecionado: BRASIL. Paraíba: Alagoinha, 25/XII/1944, fl., Xavier 1129 (JPB); Arara, 17/III/1975, fl. fr., Perazzo 218 (EAN, RB); Areia, 5/III/2001, fl. fr., Belém 2 (JPB); Cabedelo, 15/III/1997, fl., Silva 25 (JPB); Campina Grande, 8/II/1991, fl. fr., Agra 727 (JPB, RB); Cuité, 23/VI/1992, fl., Agra \& Pereira 1571 (JPB); Desterro, 
10-12/IX/1993, fl., Agra 2283 (JPB); Fagundes, I/2004, fl., Agra \& Chautems 6306 (JPB); Itaporanga, 7-10///1994, fl., Agra et al. 2555 (JPB); João Pessoa, 2/IX/1941, fl., Xavier 248 (JPB); 15/XI/1990, fl., A gra 1296 (JPB); 24/IX/2004, fl., Agra et al. 6311 (JPB); 9/XI/2005, fl. fr., Agra et al. 6494 (JPB); Juazeirinho, 7-10/I/1994, fl. fr., Agra et al. 2437 (JPB); Mamanguape, 18/I/1951, fl., Garcia 1737 (JPB); 21/XII/1989, fl., Félix 2610 (EAN, JPB); Maturéia, Pico do Jabre, I/1990, fl., Agra 1261, 1296 (JPB); 20-23/I/1997, fl., A gra et al. 4442 (JPB); Monteiro, 13-15/III/2007, fl. fr., Agra et al. 6817 (JPB); Patos, 26/V/1993, fl., Agra \& Fragoso 2117 (JPB); 0/X/1994, fl., Agra \& Góis 3198 (JPB); Rio Tinto, 31/I/1989, fl. fr., Félix 16023 (JPB); 23/II/1989, fl. fr., Agra 683 (JPB); Santa Luzia, 5/III/1993, fl., Agra \& Silva 1616 (JPB); Santa Rita, 9/IX/2005, fl., Agra et. al. 6665 (JPB); Solânea, 5/VII/2001, fl. fr., Grisi 240 (JPB).

14. Solanum paraibanum Agra, Novon 2(3): 179, f. 1. 1992. Fig. 30-31, 47

Liana, 4,0-10,0 m compr., fortemente aculeada; caule e ramos cilíndricos, hirsuto-tomentosos, marrons a ferrugíneos, tricomas estrelados sésseis, acúleos recurvos, 2,0-4,0 mm compr., ferrugíneos. Folhas simples, acúleos 2,0-5,0 mm compr., uncinados, pecíolo 1,0-3,5 cm compr., cilíndrico, hirsuto, lâmina 8,0-15,0×3,4-8,0 cm, cartácea, oblongo-elíptica, aguda no ápice e na base, raro assimétrica, 3-5 pares de lobos agudos, face adaxial lúcida, hirsuta, ferrugínea a marron, tricomas estrelados, sésseis, face abaxial tomentosa, tricomas estrelados. Inflorescência em cimeiras simples, 5-10-flora, pedúnculo $0,8-1,0 \mathrm{~cm}$, pedicelo 1,2-1,5 cm, deflexo. Flores monoclinas e estaminadas, cálice campanulado, hirsuto, aculeado, sépalas soldadas na base, tubo 0,8-1,0 mm compr., lobos 7,0-8,0×0,8-1,0 mm, linearlanceolados; corola estrelada, roxa ou púrpura, 2,8-3,0 cm diâm., pétalas soldadas no 1/4 basal, tubo 1,0-1,5 mm compr., lobos 1,0-1,4×0,6-0,7 cm, triangular-lanceolados ou ovallanceolados; filetes 1,0-1,1 mm compr., anteras 1,3-1,4 cm compr., oblongo-elípticas; ovário globoso, 1,5-2,0 mm diâm., hirsuto, estilete 1,6-1,7 cm compr. nas flores monoclinas, 0,4-0,5 cm nas estaminadas. Baga globosa, 3,0-4,0 cm diâm., não envolvida pelo cálice acrescente, aculeado, epicarpo brilhante, laranja-avermelhado no fruto maduro, hirtoferrugíneo; pedicelo frutífero deflexo, 20,0-25,0×3,0-4,0 mm, aculeado, tomentoso; sementes numerosas, 4,5-5,0× 4,4-4,5 mm, lenticelares, sub-orbiculares a reniformes, testa marrom a negra.

Exclusiva da região nordeste do Brasil, somente encontrada em remanescentes de Floresta Atlântica nos Estados de Alagoas, Bahia, Paraíba e Pernambuco (Agra 2007). Na Paraíba, a espécie foi coletada em remanescentes de Floresta Atlântica, em elevações que variam de 0-40 m de altitude.

Material examinado: BRASIL. Paraíba: João Pessoa, 9/VI/1980, fr., Moura 10 (JPB); Cidade Univeresitária, Reserva Ecológica do Departamento de Sistemática e Ecologia da UFPB, 9/XI/1982, fl. fr., Agra 448 (JPB);
8/IX/1992, fl. fr., Moura 789; Jardim de Plantas Medicinais do LTF, UFPB, 20/VIII/2008; Natuba, limite com o Mun. São Vicente Ferrer, 9/X/1997, fl. fr., Barbosa et al. 1624 (JPB); Santa Rita, V/1991, est., Agra \& Góis 1924 (JPB); 10/X/1998, fl., Viana 5491 (JPB); 15/V/2001, fl., Agra 5551 (JPB); Serraria, 8/VI/2004, fr., Gadelha-Neto 1155 (JPB).

15. Solanum polytrichum Moric., Pl. Nouv. Amer. 32, tab. 22. 1837.

Fig. 47

Arbusto ereto, 0,7-1,0 m alt., aculeado; caule e ramos cilíndricos, hirsuto-tomentosos, fusco-ferrugíneos a rubiginosos, tricomas estrelados, estipitados, acúleos aciculares, amarelos a ferrugíneos, 0,3-0,5 cm. Folhas geminadas, acúleos aciculares, 2,0-10,0 $\mathrm{mm}$, amarelos, pecíolo 2,0-4,0 cm compr., subcilíndrico, lâmina 0,8-26,0× 6,5-10,0 cm, cartácea, elíptica, obeliptica a oval-elíptica, inteira ou com 4-5 pares de lobos, agudos, ápice agudo, base aguda ou oblíqua, face adaxial escabro-hirsuta, face abaxial tomentoso-hirsuta, tricomas estrelados, longoestipitados. Inflorescência 5-10 flora, pedúnculo $0,2-1,0 \mathrm{~cm}$ compr., pedicelo 1,5-2,0 cm, acúleos aciculares 1,0-3,0 mm. Flores monoclinas e estaminadas, cálice campanulado, 5-partido, tubo 2,0-3,0 mm compr., lobos 8,0-12,0×2,0-3,0 mm, triangulares, corola estrelada, alva a esverdeada, $2,5-3,0 \mathrm{~cm}$ diâm., 5-partida, tubo 1,0-1,5 mm compr., lobos 13,0-15,0× 1,5-2,0 mm, linear-lanceolados, filetes 2,0-3,0 mm, anteras 5,0-6,0 mm compr., linear-lanceoladas; ovário subgloboso, ca. $0,1 \mathrm{~cm}$ diâm., glandular-pubérulo, estilete 7,0-8,0 mm compr., nas flores monoclinas, 3,0-4,0 cm nas estaminadas. Baga globosa, 1,2-1,5 cm diâm., envolvida pelo cálice acrescente, inflado, hirsuto, aculeado, epicarpo brilhante, verde a amarelo, glabro; pedicelo frutífero ereto, 10,0-25,0× 2,0-3,0 $\mathrm{mm}$, aculeado, hirsuto; sementes numerosas, 2,4-2,5×2,5-3,0 mm, sub-reniformes, beges.

Exclusiva da flora brasileira, ocorrendo em áreas de domínio da Floresta Atlântica, nos Estados de Alagoas, Bahia, Espírito Santo, Sergipe, Paraíba, Piauí e Rio de Janeiro (Agra 2007). Na Paraíba, é uma espécie rara conhecida de apenas três coletas, em remanescentes de Floresta Atlântica, cuja área é bastante ameaçada pela exploração imobiliária.

Material examinado: BRASIL. Paraíba: Conde, Mata Redonda, 24/II/1987, fl., Agra 563 (JPB); Santa Rita, V/1991, fl., Agra \& Góis 1925 (JPB); 27/VI/2000, fl., Agra \& Góis 5580 (JPB); 10/VIII/2008, fl., fr., A gra et al. 7007 (JPB, NY, UT).

Material adicional examinado: BRASIL. Bahia: Barra do Choça, 1454'22,2”S e 40 34'9,9”'W, 26/III/2007, fl. fr., Agra et al. 6997 (JPB).

16. Solanum rhytidoandrum Sendtn., in Mart., Fl. bras. 10: 85.1846.

Fig. 32-36, 47

Arbusto ereto, 0,7-2,5 m alt., aculeado; caule e ramos cilíndricos, escabros, tomentosos, glabrescentes, tricomas glandular-estrelados e multiangulados, sésseis e estipitados, 
acúleos recurvos no ápice, 0,2-0,5 cm. Folhas solitárias, pecíolo 1,0-2,0 cm compr., atenuado, subinerme, acúleos 2,0-3,0 mm, lâmina 6,0-18,0×3,0-8,0 cm, cartácea, elíptica, ovalelíptica ou elíptica, inteira, ápice agudo, base cuneada ou assimétrica, face adaxial rugosa, escabra ou tomentosa, tricomas glandular-estrelados, sésseis, face abaxial velutina a tomentosa, amarelada. Inflorescência em cimeira ramificada, 20-multiflora, pedúnculo $3,5-4,0 \mathrm{~cm}$, pedicelo 4,0-5,0 mm, articulado. Flores monoclinas e estaminadas, cálice campanulado, sépalas soldadas na base, tubo 1,5-2,0 mm compr., lobos linear-lanceolados, agudos a acuminados, 4,0-6,0×1,5-2,0 mm, corola estrelada, alva, 2,5-3,0 cm diâm., pétalas soldadas na base, tubo 1,5-2,5 mm compr., lobos 1,0-1,2×0,2-0,3 cm, oblongos ou linearlanceolados; filetes 1,0-1,5 mm, anteras 8,0-10,0 mm compr., oblongo-lanceoladas, ovário subgloboso, 1,5-2,0 mm diâm., hirsuto, estilete 1,2-1,5 cm compr., 0,4-0,5 cm nas flores estaminadas. Baga subglobosa, 1,5-2,0 cm diâm., não envolvida pelo cálice frutífero, inerme a subinerme, epicarpo verde-variegado a marron, glanduloso-viscoso, tricomas glandular-estipitados; pedicelo frutífero ascendente, 5,0-7,0 $\times 1,5-2,5 \mathrm{~mm}$, aculeado, tomentoso; sementes 4,0-4,5×3,0-3,5 mm, ovóides a reniformes, beges.

Espécie neotropical, exclusiva da América do Sul com distribuição no Brasil, Bolívia e Paraguai, ocorrendo em áreas do semi-árido, em elevações de 0-1.000 m (Agra 2001). Espécie comum na Paraíba, Solanum rhytidoandrum foi encontrada em vegetação secundária, no litoral, brejos de altitudes, matas serranas e em diferentes tipos de microrregiões da caatinga, inclusive em áreas de conservação. É uma espécie heliófila, habitando solos argilosos, argilo-humosos e rupestres.

Material selecionado: BRASIL. Paraíba: Araruna, 28-31/VIII/2003, fl., A gra et al. 6227 (JPB); Areia, 9/IX/1974, fl. fr., Xavier 3632 (JPB); 12/X/1992, fl. fr., Agra \& Bhattacharyya 1759 (JPB); 17/VI/2003, fl. fr., A gra et. al. 6001 (JPB); Boa Vista, 27-29/IV/1994, fl. fr., A gra et al. 2891 (JPB); Cabaceiras, 29/VIII/1993, fl., Agra et al. 2237 (JPB); Campina Grande, 2/IV/1988, fl., Agra 653 (JPB, RB); 1/I/1989, fl. fr., Agra 1283 (JPB); 23/VI/1995, fl., Agra et al. 3374 (JPB); Cruz do Espírito Santo, 29/IX/1992, fl., Moura 837 (JPB); Itaporanga, 7-10/I/1994, fl., Agra et al. 2452 (JPB); João Pessoa, 19/XI/1971, fl. fr., Correia 73 (JPB); 21/XI/1993, fl. fr., Agra \& Bhattacharyya 2404 (JPB); 9/XI/2005, fl. fr., Agra et al. 6493 (JPB); Mamanguape, 21/XII/1989, fl. fr., Félix 2607 (JPB); Maturéia, Pico do Jabre, 1-2/IV/1991, fl., Agra \& Barbosa 1865 (JPB); 18/I/1997, fl., Agra et al. 3938 (JPB); 12/X/2000, fl. fr., Agra \& Sarmento 5554 (JPB); 13-14/IV/2002, fl., A gra et al. 5778 (JPB); 14/IV/2005, fl., Agra et al. 6438 (JPB); 13/VIII/2008, fl. fr., Agra et al. 7017 (JPB, NY, UT); Santa Rita, 3/X/1984, fl., Agra \& Góis 486 (JPB, RB); 31/X/1995, fl. fr., A gra et al. 3448 (JPB); São João do Cariri, 29-31/X/1993, fl., Agra et al. 2375 (JPB); (JPB); Serra Branca, 8-11/III/2002, fl. fr., Agra et al. 5721 (JPB); 26/IV/2006, A gra et al. 6716 (JPB); Tacima, 8-11/III/2002, fl., Agra et al. 5678 (JPB).

\section{Solanum sp.}

Fig. 46

Arbusto ereto, 1,0-1,5 m alt., inerme; caule e ramos cilíndricos, pilosos, lúcidos, marrons. Folhas alternas, geminadas, pilosas, pecíolo 3,0-7,0 mm compr., alado, lâmina 3,5-5,0×2,0-3,0 cm, membranácea, oval a oval-elíptica, ápice agudo, base atenuada, margem inteira, face adaxial glabra, pilosa na vervura principal, face abaxial cinéreo-pilosa em toda a lâmina, tricomas simples e dendriticos. Inflorescência em cimeira simples, 5-20-flora, séssil, pedicelo 7,0-8,0 mm compr., 5-costado, piloso, tricomas dendríticos. Flores monoclinas, pilosas, cálice campanulado, tubo 1,0-1,5 mm compr., lobos 4,0-5,0×2,0-2,5 mm, deltóides a triangulares, cuspidados; corola rotáceo-estrelada, alva, 1,0-1,5 cm diâm., tubo 1,0-1,5 mm compr., lobos 3,0-4,0×3,0-3,8 mm, triangulares, ápice agudo, filetes $>1,0 \mathrm{~mm} \mathrm{~mm}$ compr. da porção livre, anteras 3,5-4,0 mm compr., obelípticas; ovário subgloboso, ca. 1,0 mm diâm., glabro, estilete 5,0-6,0 mm compr., cilíndrico. Fruto não visto.

Espécie rara na Paraíba, coletada em área da caatinga, às margens de um riacho seco, em terreno arenoso, registrada de apenas uma coleta. É uma espécie pertencente a Solanum sect. Geminata, com grande afinidade com Solanum arenarium Sendtn., cujo tipo é da Bahia.

Material examinado: BRASIL. Paraíba: Itaporanga, próximo à ponte, 4/III/1993, fl., Agra \& Silva 1603 (JPB).

18. Solanum stagnale Moric., Pl. Nouv. Amer. 34, tab. 23. 1837.

Fig. 47

Arbusto, ereto, 0,7-1,0 m alt., aculeado; caule e ramos cilíndricos, tomentoso-hirsutos a tomentoso-lanosos, tricomas estrelados, longo-estipitados, acúleos aciculares, 1,0-1,5 cm. Folhas solitárias, pecíolo 1,0-2,0 cm, alado, acúleos aciculares, 0,5-2,0 cm compr., indumento e tricomas semelhantes ao dos ramos, lâmina 8,5-22,5×5,0-13,0 cm, cartácea a coriácea, oval a oval-elíptica, 4-5 pares de lobos, agudos, profundos, inteiros ou levemente denteados, ápice agudo, base cuneada, decurrente, face adaxial escabra a velutina, face abaxial tomentoso-velutina, amarela a cinérea, tricomas estrelados e multiangulados, longos-estipitados, acúleos aciculares, 1,0-2,3 cm compr., acompanhando a venação principal. Inflorescência lateral, monocasial, helicóide, 2-6-flora; pedúnculo 1,0-1,5 cm compr., inerme, pedicelos 0,5-0,6 cm compr., articulados, inermes, amareloferrugíneo. Flores 1-2 monoclinas e estaminadas, cálice campanulado, soldado na base, tubo $6,0-8,0 \mathrm{~mm}$ compr., lobos 7,0-8,0-1,0×0,5-0,6 cm, oval-lanceolados, corola rotáceo-estrelada, cerúlea ou lilás, 3,0-4,0 cm diâm., tubo 0,6-0,8 mm compr., lobos 1,7-1,8×0,5-0,7 cm, lanceolados, filetes $1,0-1,5 \mathrm{~mm}$, anteras $0,7-0,8 \mathrm{~cm}$ compr., lanceoladas, ovário subgloboso, 1,0-2,0 mm diâm., denso-pubescente, estilete 1,2-1,5 cm compr. nas flores monoclinas, 2,3-3,0 mm nas estaminadas. Baga globosa, 2,5-3,0 cm, hirsuta, não envolvida pelo cálice frutífero, aculeado, epicarpo verde- 
variegado a amarelo-claro, hirsuto; pedicelo frutífero deflexo, $6,0-12,0 \times 4,0-6,0 \mathrm{~mm}$, inerme a subinerme, tomentoso a lanuginoso; sementes não vistas.

Espécie neotropical, exclusiva da flora brasileira, registrada para a Bahia (Whalen et al. 1981), de onde foram coletados os tipos, e para a Paraíba (Agra 2007). Na Paraíba, Solanum stagnale é uma espécie ameaçada conhecida de apenas uma coleta, realizada no litoral, em terreno arenoso, em área com forte pressão antropica.

Material examinado: BRASIL. Paraíba: Conde, Granja da Varig, 4/III/1993, fl., Agra \& Góis 617 (JPB).

Material adicional examinado: BRASIL. Bahia: Valença, área de restinga, 2/XI/1990, fl. fr., Carvalho 3219 (CEPEC, JPB, NY); Una, 21/XI/1965, fl., Belém \& Magalhães 1078 (UB).

19. Solanum stipulaceum Roem. et Schult., Syst. Veg. 4: 662. 1819.

Fig. 47

Arbusto, ereto, 1,5-2,0 m alt., inerme; caule e ramos cilíndricos, estriados, dicotômicos com pseudoestípulas foliáceas, 2,0-6,0×2,0-2,0 mm, oval-lanceoladas, tomentosovelutinas, tricomas estrelados, sésseis e estipitados. Folhas solitárias, pecíolo 0,5-3,0 cm compr., canaliculado, lâmina 4,2-12,5×1,7-3,2 cm, cartácea, elíptica, ápice acuminado a agudo, base aguda, ambas as faces cinéreas, velutinas, opacas, tricomas estrelados e multiangulados, sésseis e estipitados. Inflorescência em cimeira dicotômica, multiflora, pedúnculo 2,0-5,5 cm compr., pedicelo 3,0-4,0 $\mathrm{mm}$ compr., indumento e tricomas semelhantes aos do pecíolo. Flores monoclinas, cálice campanulado, sépalas parcialmente soldadas, tubo 2,0-4,0 mm compr., lobos 2,0-3,5 mm compr., lanceolados, corola rotáceo-estrelada, lilás a púrpura, pétalas soldadas no 1/4 basal, tubo 3,0 mm compr., lobos 6,0-7,0 mm compr., filetes 1,5-1,6 mm compr., anteras ca 4,0-5,0 mm compr., oblongas, ovário subgloboso, 1,0-1,2 mm diâm., hirsuto, estilete 6,0-7,0 mm compr., cilíndrico. Baga subglobosa, 1,0-1,2 cm diâm., não envolvida pelo cálice frutífero, inerme, epicarpo fosco, verde-cinéreo, pubescente, tricomas estrelados; pedicelo frutífero ereto, 10,0-12,0× 1,5-2,0 mm, inerme, estrelado-pubescente; sementes numerosas, 1,8-2,0×1,7-2,0 mm, subreniformes, pardas.

De acordo com Roe (1972), é uma espécie exclusiva da flora brasileira encontrada em matas secas e à margem de estradas do nordeste e sudeste do Brasil, em áreas montanhosas, em altitudes que variam de 500 a $1.000 \mathrm{~m}$. Conhecida principalmente da Serra do Espinhaço em Minas Gerais, Serra de Itiuba e Serra da Ibiapaba, no Ceará, sua ocorrência também é comum na Chapada Diamantina (Bahia), Serra da Borborema (Paraíba e Pernambuco) e em outras áreas montanhosa do centro-oeste. Na Paraíba, a espécie foi encontrada em altitudes que variam de 600 a $1.170 \mathrm{~m}$, em áreas de rochas graníticas, em duas áreas de conservação: Unidade de Conservação Estadual do Pico do Jabre e RPPN Fazenda Almas.
Material selecionado: BRASIL. Paraíba: Maturéia, Serra de Teixeira, 1-2/IV/1991, fl., Agra \& Barbosa 1639 (JPB); 16/IV/1993, fl. fr., Agra et al. 1948 (JPB, MO, NY); 12/VII/1997, fl., Agra et al. 4045 (JPB, RB); 27-29/IX/1997, fl., Agra et al. 4343 (JPB); 20-23/XII/1997, fl., Agra et al. 4367 (JPB); 18-30/I/1998, fl. fr., Agra \& Silva 4882 (JPB, RB); 23/IV/1998, fl. fr., Agra \& Silva 5187 (JPB); 18-20/VII/1998, fl., A gra et al. 5370 (JPB); 13-14/IV/2002, Agra et al. 5785 (JPB); 4/VIII/2005, fl., Agra et al. 6667 (JPB); Serra Branca, VI/1998, fl. fr., Agra 5976 (JPB); 2/VII/1999, fl., A gra \& Góis 5515 (JPB); 8-11/III/2002, fl., Agra et al. 5714 (JPB); 12/VIII/2008, fl. fr, Agra et al. 7014 (JPB, NY, UT).

20. Solanum stramoniifolium Jacq., Misc. Austriac. 2: 298. 1781.

Fig. $37-40,47$

Arbusto ereto, 1,0-2,0 m alt., fortemente aculeado; caule e ramos cilíndricos, tomentoso-pulverulento, tricomas estrelados multiangulados, acúleos aciculares, esparsos, 1,0-2,0 cm. Folhas solitárias, pecíolo 5,0-10,0(-25) cm compr., cilíndrico, acúleos aciculares, 0,4-1,4 cm compr., lâmina 15-22×8,0-18 cm, oval a oval-elíptica, membranácea a cartácea, 3-5-pares de lobos, deltóides, ápice agudo, base sub-cordada, sagitada ou oblíqua, face adaxial escabra, tricomas simples e estrelados, multiangulados, sésseis, face abaxial tomentosa, tricomas estrelado-estipitados, purpúreos, acúleos aciculares, 0,4-1,0 cm. Inflorescência em cimeira lateral, 9-20-flora, sub-séssil, pedicelo 0,8-1,0×1,5-2,0 mm compr., cilíndrico. Flores monoclinas e estaminadas, cálice campanulado, tubo 2,5-3,5 mm compr., geralmente com um anel de nectários externos, ca. 1,0 mm, lobos 0,5-0,8 mm compr., truncados, corola estrelada, alva, pétalas soldadas, tubo 1,0-1,5 mm compr., lobos $0,8-1,2 \mathrm{~cm}$ compr., oblongos a linear-lanceolados, filetes 1,0-1,2 mm compr., anteras lanceoladas, duas maiores, $0,9-1,0 \mathrm{~cm}$ compr., três menores, 8,0-8,5 mm; ovário globoso, 1,5-2,0 mm diâm., estrelado-pubescente, estilete glabro, 0,9-1,0 cm compr., 0,3-0,4 cm nas flores estaminadas. Baga globosa, $1,5-2,0 \mathrm{~cm}$ diâm., não envolvida pelo cálice frutífero, subinerme, epicarpo avermelhado na maturação, estrelado-pubescente, tricomas estrelados, decíduos; pedicelo frutífero ascendente, 10,0-15,0×1,5-2,0 mm, inerme, estrelado-pubescente; sementes numerosas, 2,5-3,0×2,4-2,9 mm, lenticulares, oval a reniformes, beges.

De acordo com Whalen et al. (1981), Solanum stramoniifolium é uma espécie neotropical, com ampla distribuição na América tropical, ocorrendo em vegetação secundária de florestas úmidas da América Central e América do Sul. No Brasil foi registrada para os Estados do Amapá, Amazonas, Bahia, Ceará, Maranhão, Pará, Pernambuco, Paraíba e Roraima (Agra 2007). Na Paraíba, é uma espécie somente encontrada na Mata do Buraquinho, um remanescente de Floresta Atlântica do Jardim Botânico de João Pessoa. 
Material examinado: BRASIL. Paraíba: João Pessoa, Mata do Buraquinho, 13/V/1985, fl. fr., Agra \& Bhattacharyya 551 (JPB); 25/III/1989, fl. fr., Agra 796 (JPB); 27/III/2001, fl., Agra \& Sarmento 5517 (JPB); 21/VI/2001, fl. fr., Agra 5964 (JPB); 12/IV/2007, fl. fr., Agra \& Silva 6995 (JPB); 21/VIII/2008, fl. fr, Agra et al. 7031 (JPB, UT).

21. Solanum swartzianum Roem. \& Schult., Syst. 4: 602. 1819.

Fig. 47

Arvoreta, 1,0-3,0 m alt., inerme; caule e ramos cilíndricos, complanados no ápice, lepidotos, dourado-claro, tricomas peltados. Folhas isoladas ou geminadas, pecíolo $0,4-1,0 \mathrm{~cm}$ compr., torcido, canaliculado, lepidoto, tricomas peltados, lâmina 8,0-21,0×3,5-7,5 cm, cartácea, elíptica, ápice acuminado, base cuneada ou oblíqua, margem inteira levemente revoluta, face adaxial glabrescente, tricomas escamosos esparsos, face abaxial denso-lepidota, tricomas peltados e estrelado-peltados. Inflorescência em cimeira escorpióide, 5-7-flora, pedúnculo 4,0-5,0 cm compr., pedicelo 0,5-1,0 cm compr., lepidoto. Flores monoclinas, cálice campanulado, 5-fendido, tubo 5,0-7,0 mm compr., externamente lepidoto, lobos 1,5-2,0 mm, lanceolados, corola rotáceo-estrelado, alvo-esverdeada, 1,0-1,5 cm diâm., tubo 2,0-3,0 mm compr., lobos 0,7-0,8×0,3-0,4 cm, oblongolanceolados, filetes 1,0-1,5 mm, anteras 5,0-6,0 mm compr., oblongas, introrsas, ovário globoso, 1,0-2,0 mm de diâm., estilete 6,0-8,0 mm. Baga globosa, 1,0-1,5 cm diâm., envolvida pelo cálice acrescente, inerme, lepidoto, tubo 6,0-8,0 cm compr., epicarpo brilhante, verde-escuro, glabro; pedicelo 10,0-12,0×2,0-2,5 mm, inerme, lepidoto; sementes não vistas.

Espécie exclusiva da América do Sul, com distribuição na Venezuela (Benitez 2006) e Brasil, registrada para os Estados da Bahia, Espírito Santo, Minas Gerais, Rio de Janeiro, São Paulo, Roraima (Carvalho 1996), Paraná e Santa Catarina (Mentz \& Oliveira 2004). Na Paraíba, a espécie é conhecida de apenas uma coleta, realizada há mais de 50 anos, em uma mata de brejo de altitude, provavelmente extinta no Estado.

Material examinado: BRASIL. Paraíba: Areia, matas do Dr. Mainardo Cabral, fr., 10/VI/1953, Moraes 795 (EAN, RB); 12/VIII/2008, bot., Agra et al. 7012 (JPB, UT).

Material adicional examinado: BRASIL. Bahia: Camacã, Reserva Florestal Pau Brasil, 23/IV/1983, fl., Carvalho et al. 1887 (CEPEC, RB).
22. Solanum torvum Sw. Prod. 47. 1788.

Fig. 41-45, 47

Arbusto ereto, 1,5-2,0 m alt., aculeado; caule e ramos cilíndricos, tomentosos, tricomas estrelados, acúleos esparsos, cônicos, eretos ou recurvos, 0,5-1,5 cm. Folhas solitárias, subinermes, acúleos 4,0-6,0 mm, pecíolo 2,5-4,0 cm, cilíndrico, lâmina 8,5-25,0×8,0-24,0 cm, cartácea, oval a oval-elíptica, lobada ou repanda, ápice agudo, base oblíqua ou cordiforme, face adaxial escabra, tricomas porrecto-estrelados, sésseis, face abaxial tomentosa, tricomas semelhantes aos da face adaxial. Inflorescência 2-5-ramificada, multiflora, pedúnculo 4,0-5,0 mm compr., pedicelo 0,8-1,0 cm compr., glanduloso-piloso. Flores monoclinas e estaminadas, cálice campanulado, 5-fendido, tubo 2,0-2,5 mm compr., glanduloso-pubérulo, glabro nas sinuosidades, lobos 2,0-2,5 mm, cuspidados; corola rotáceo-estrelado, alva, 2,0-2,5 cm diâm., tubo 2,0-2,5 mm compr., lobos 2,0-2,5 mm compr., triangular-lanceolados; filetes 1,5-2,0 mm, anteras 5,0-6,0 mm compr., linear-elípticas, levemente inflexas, ovário globoso, 1,0-2,0 mm de diâm., glandular-pubérulo no $1 / 4$ terminal, estilete $0,8-1,3 \mathrm{~cm}$ compr., 0,3-0,4 cm nas flores estaminadas. Baga globosa, 1,2-1,5 cm diâm., não envolvida pelo cálice frutífero, inerme, epicarpo fosco, verde-claro, esbranquiçado a marrom no fruto maduro, glabro; pedicelo frutífero ascendente, anguloso, 15,0-18,0× 2,0-4,0 mm, inerme, glabrescente, tricomas glandulares; sementes numerosas, 2,0-3,0x 2,5-3,0 mm, discóides, pardas.

Espécie nativa das Antilhas, com dispersão em muitas regiões tropicais do Velho e do Novo Mundo (D'Arcy 1973). No Brasil, foi registrada para as regiões nordeste e sudeste do país (Agra 2007). É uma espécie comum na Paraíba, encontrada em terrenos abandonados de solos arenoargilosos e argilosos, próximo a habitações.

Material examinado: BRASIL. Paraíba: Cabaceiras, 29/VII-1/VIII/1993, fl. fr., A gra 2236 (JPB); Campina Grande, 2/I/1989, fl. fr., Agra \& Bhattacharyya 1248 (JPB); João Pessoa, 29/XI/1990, fl. fr., Agra \& Góis 1295 (JPB); VI/1992, fl., Agra 1477 (JPB); Solânea, 15/III/2001, fl. fr., Grisi 157 (JPB); 5/VII/2001, fl. fr., Grisi 236 (JPB).

\section{Agradecimentos}

Ao Conselho Nacional de Desenvolvimento Cientifico e Tecnológico (CNPq), pelo apoio financeiro e bolsas concedidas aos autores, aos curadores dos herbários nacionais e internacionais, pelo livre acesso às suas dependências e empréstimo do material examinado, especialmente a Dra. Maria Regina de V. Barbosa, curadora do JPB, ao Dr. Jnanabrata Bhattacharyya pela revisão do abstract, a Dulce G. Oliveira pelo apoio técnico, e a Madson Roberto pelas ilustrações. 

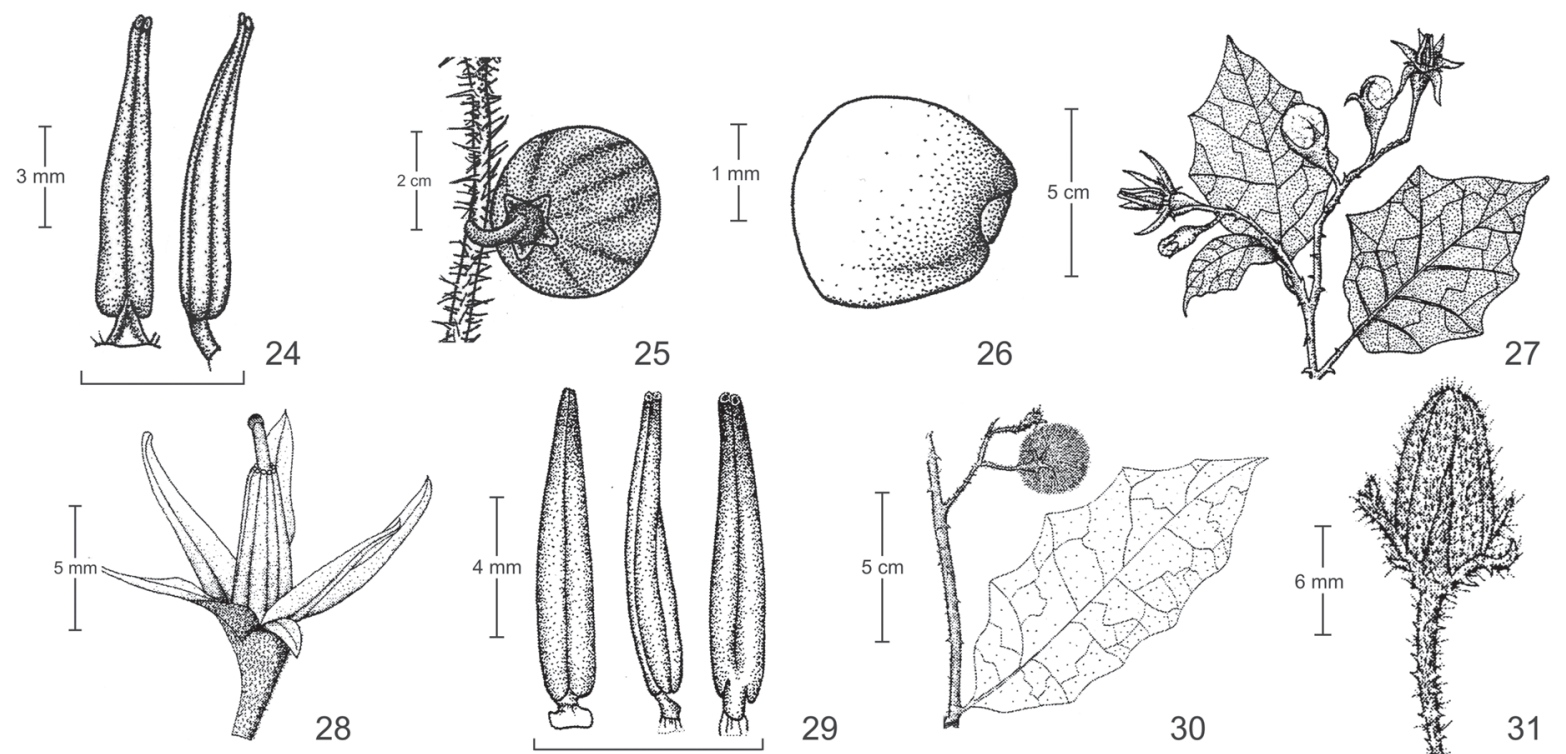

26
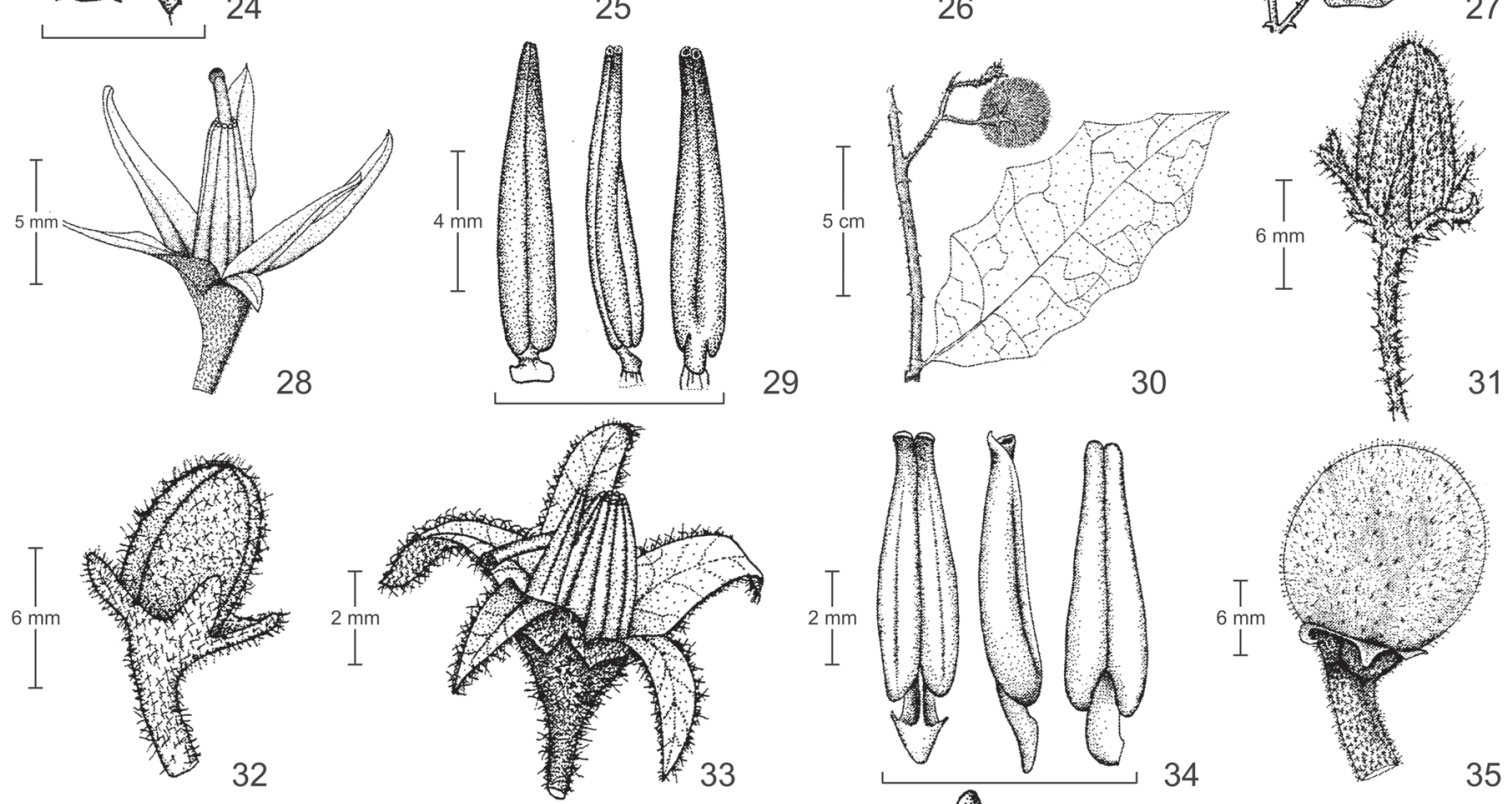

29
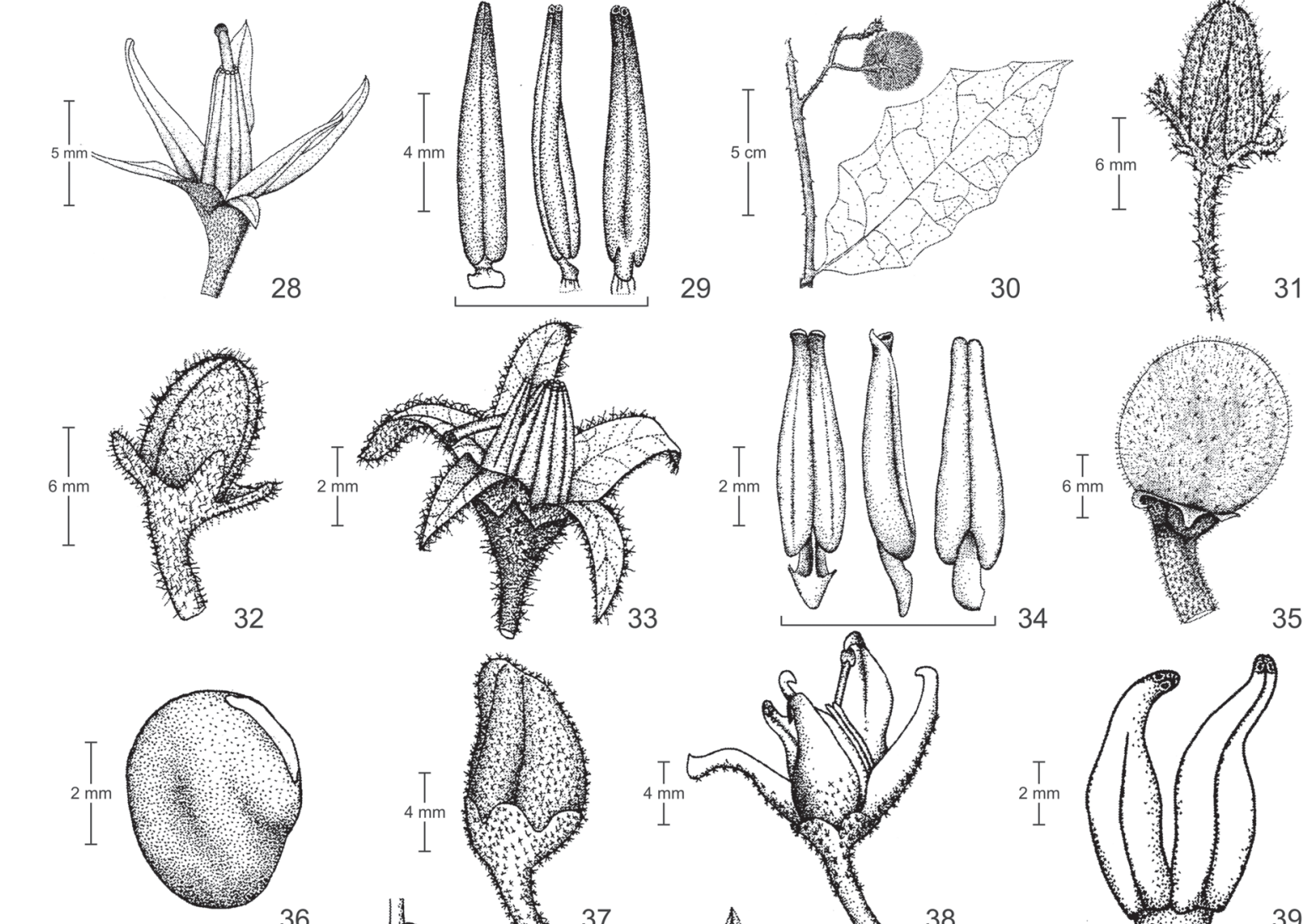

35
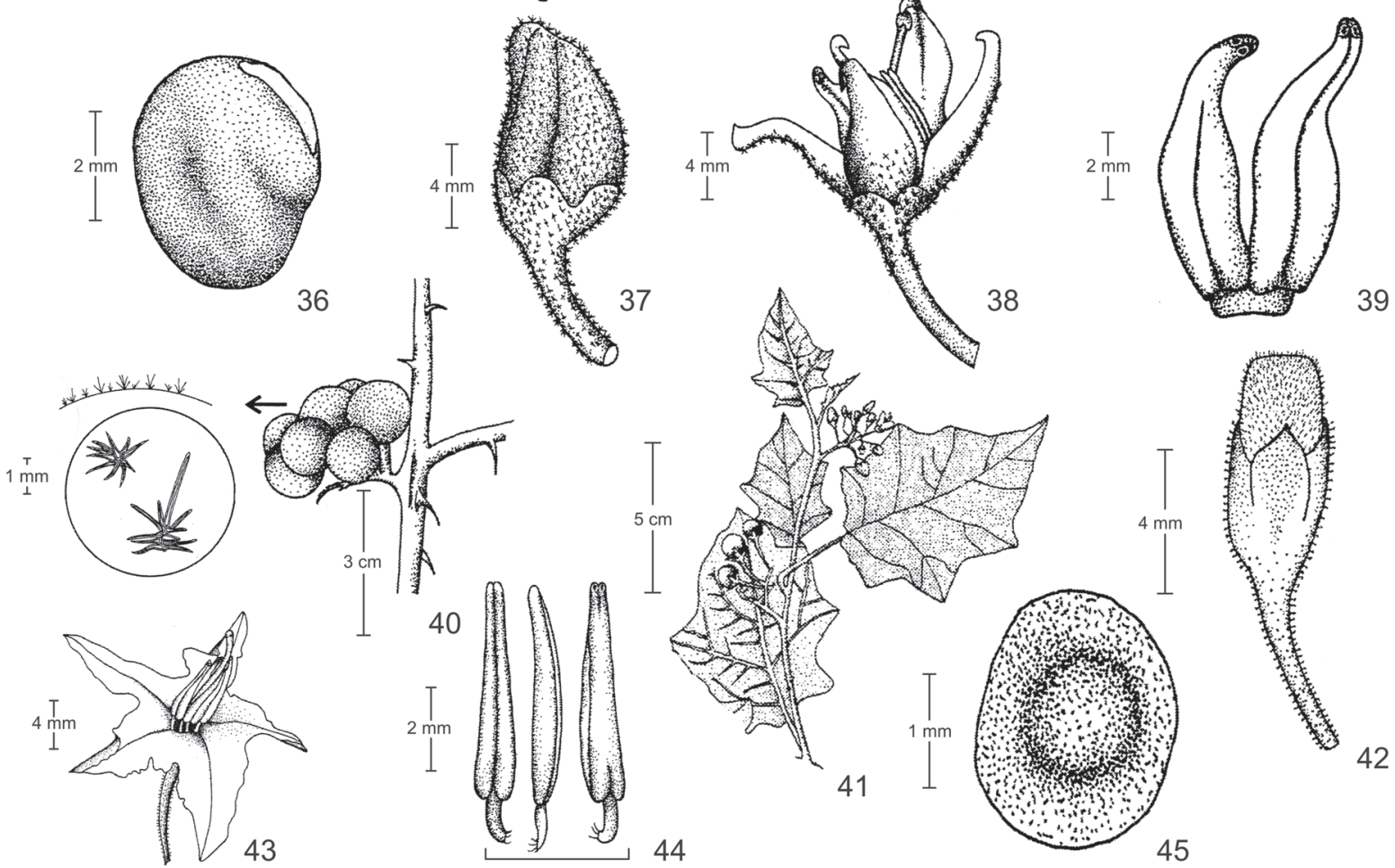

36
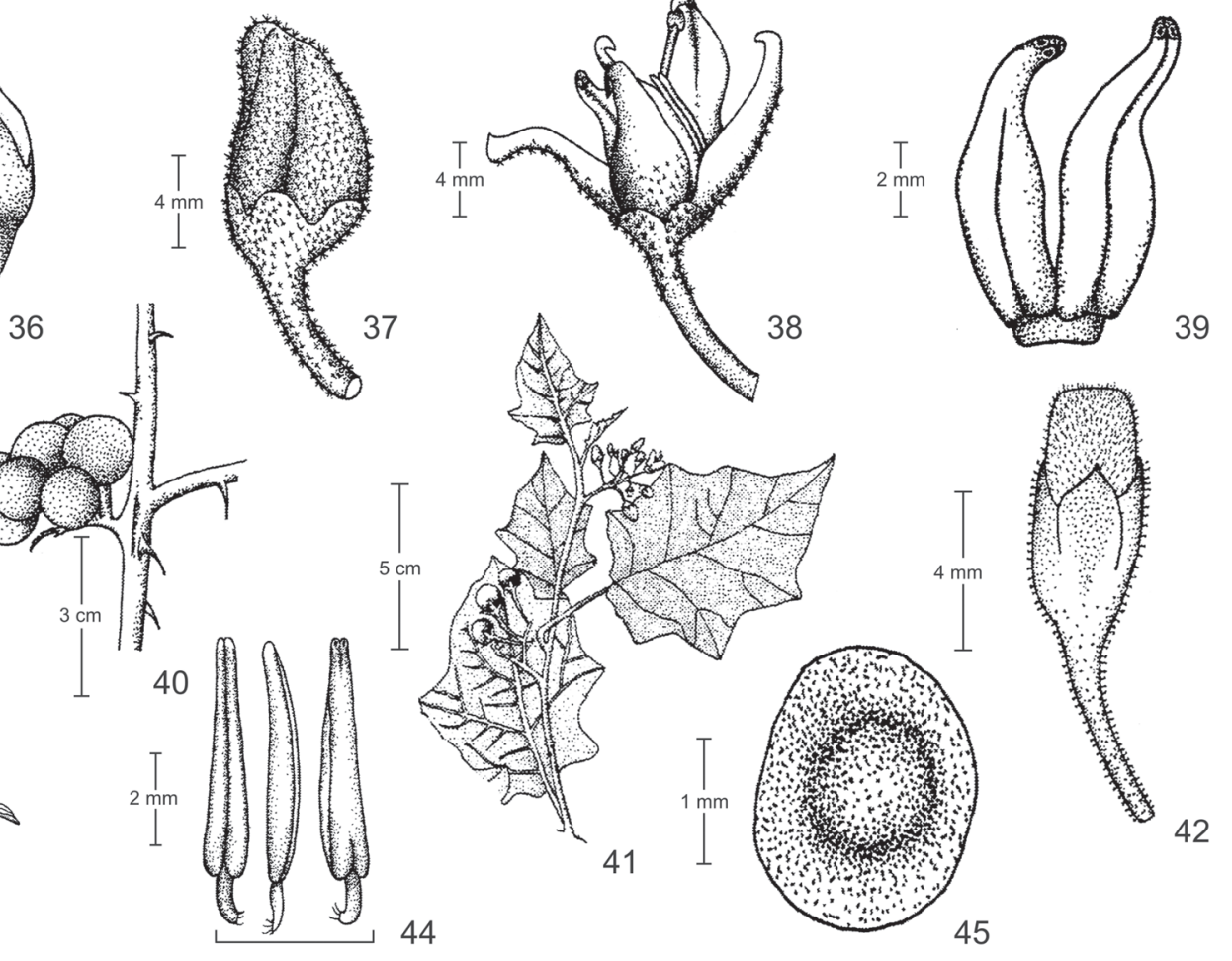

Figuras 24-26. Solanum palinacanthum Dunal (Agra 643). 24. Estames, visão frontal e perfil. 25. Fruto. 26. Semente. Figuras 27-29. Solanum paludosum Moric. (Agra 1100). 27. Ramo florido e frutificado. 28. Flor isolada. 29. Estame, vista frontal, perfil e vista dorsal. 30-31. Solanum paraibanum Agra (Agra \& Góis 1924). Ramo frutificado. 31. Botão floral. 32-36. Solanum rhytidoandrum Sendtn. (Agra et al. 6493). 32. Botão floral. 33. Flor. 34. Estame, vista frontal, perfil e vista dorsal. 35. Fruto. 36. Semente. 37-40. Solanum stramoniifolium Jacq. (Agra \& Silva 6995). 37. Botão floral. 38. Flor. 39. Estame, vista dorsal. 40. Frutos e detalhe dos tricomas do epicarpo. 41-45. Solanum torvum Sw. (Agra \& Góis 1295). 41. Ramo florido e frutificado. 42. Botão floral. 43. Flor. 44. Estame, vista frontal, perfil e vista dorsal. 45. Semente. 


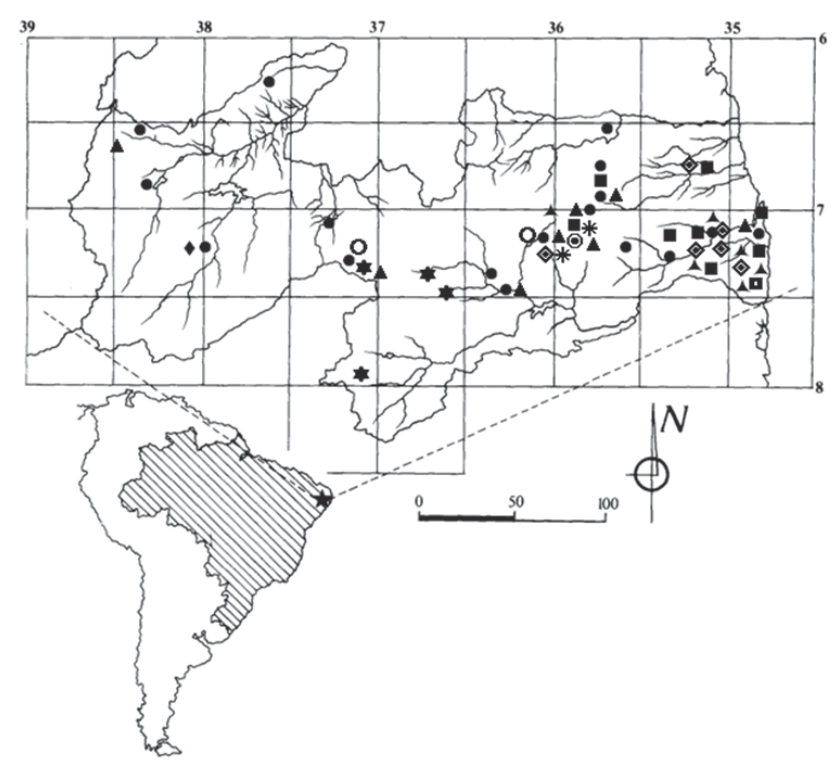

Figura 46. Mapa de distribuição geográfica de Solanum na Paraíba, Brasil:

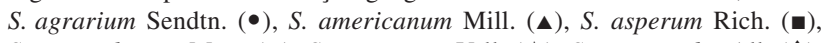
S. asterophorum Mart. (*), S. caavurana Vell. (^), S. capsicoides All. ( $\diamond)$, S. crinitum Lam. (ם), S. jabrense Agra \& M. Nee (*), S. melissarum Bohs (๑) e S. ovum-fringillae (Dunal) Bohs (০), Solanum sp. (•).

\section{Referências bibliográficas}

Agra, M.F. 1992. A New species of Solanum section Micracantha (Solanaceae) from Northeastern Brazil. Novon 2: 179-181.

Agra, M.F. \& Nee, M. 1997. A New Species of Solanum subgenus Leptostemonum (Solanaceae) from Northeastern Brazil. Brittonia 49: 350-353.

Agra, M.F. 1999a. Diversity and distribution of Solanum subgenus Leptostemonum in North-East of Brazil. Pp. 197-203. In: M. Nee; D. Symon; R.N. Lester \& J.P. Jessop (eds.). Solanaceae IV: Advances in Biology and Utilization. Kew, Royal Botanical Gardens.

Agra, M.F. 1999b. A New Species of Solanum subgenus Leptostemonum (Solanaceae) from Chapada da Diamantina, Bahia, Brazil. Novon 9: $292-295$.

Agra, M.F. 2001. Diversity and Biogeography of Solanum sect. Erythrotrichum Child. Pp. 53-60. In: R.G. Van Den Berg; G.W.M. Barendese; G.M. Van Der Weerden \& C. Mariani (orgs.). Solanaceae V: Advances in Taxonomy and Utilization. Holanda, Nijmegen, Nijmegen University Press.

Agra, M.F.; Galassi, S.; Nee, M. \& Silva, M.M. 2003. Lista das plantas Vasculares de Catolés, Chapada Diamantina, Bahia, Brasil: Solanaceae. Boletim de Botânica (USP) 21: 388-389.

Agra, M.F.; Barbosa, M.R.V. \& Stevens, W.D. 2004. Levantamento Florístico Preliminar do Pico do Jabre, Paraíba, Brasil. Pp. 123-138. In: K.C. Pôrto; J.J.P. Cabral \& M. Tabarelli (orgs.). Brejos de Altitude em Pernambuco e Paraíba/ História Natural, Ecologia e Conservação. Brasília, Ministério do Meio Ambiente.

Agra, M.F. 2004. Sinopse Taxonômica de Solanum sect. Erythrotrichum (Solanaceae). Pp. 192-211. In: J.O. Rangel-Ch.; J.C. Aguirre; M.G.C. Andrade \& D.G. Cañas (orgs.). VIII Congresso Latinoamericano e II Colombiano de Botânica. Bogotá 2004. ARFO Editores e Impressos Ltda.

Agra, M.F. 2006. Solanaceae. Pp. 146-148. In: M.R.V. Barbosa; C. Sothers; S. Mayo \& C. Gamarra (orgs.). Checklist das Angiospermas do Nordeste. Brasília, Ministério da Ciência e Tecnologia.

Agra, M.F. 2007. Diversity and Distribution of Solanum subgenus Leptostemonum in Brazil. Pp. 31-43. In: D.M. Spooner; L. Bohs; J. Giovannoni; R.G. Olmstead \& D. Shibata (orgs.). Acta Horticulturae - VI International Solanaceae Conference: Genomics Meets Biodiversity. Madison, Wisconsin, International Society for Horticultural Science, v. 745

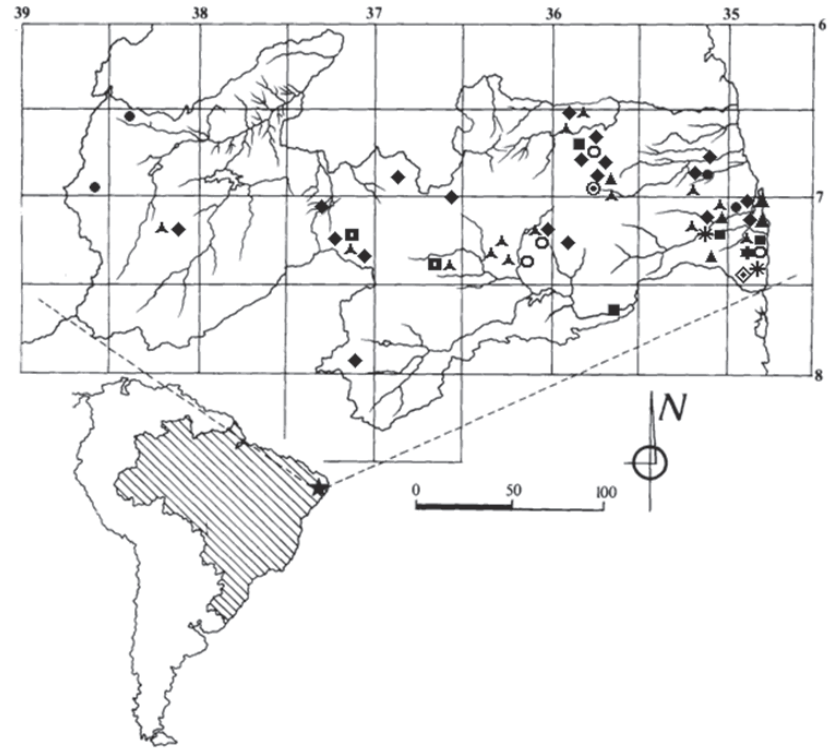

Figura 47. Mapa de distribuição geográfica de Solanum na Paraíba, Brasil: S. palinacanthum Dunal $(\bullet)$, S. paludosum Moric. (^), S. paniculatum L. (•), S. paraibanum Agra (घ), S. polytrichum Moric. (*), S. rhytidoandrum Sendtn. $(\boldsymbol{\wedge})$, S. stagnale Moric. $(\diamond)$, S. stipulaceum Roem. et Schult. (ם), S. stramoniifolium Jacq. (*), S. swartzianum Roem. \& Schult. (๑) e S. torvum Sw. (0).

Barbosa, M.R.V.; Agra, M.F.; Sampaio, E.V.S.B., Cunha, J.P. \& Andrade, L.A. 2004. Diversidade Florística da Mata de Pau Ferro, Areia, Paraíba. Pp. 111-122. In: K.C. Pôrto; J.J.P. Cabral \& M. Tabarelli (orgs.). Brejos de Altitude em Pernambuco e Paraíba/ História Natural, Ecologia e Conservação. Brasília, Ministério do Meio Ambiente.

Benitez, C. 2006. Solanaceae. Pp. 194-246. In: J.A. Steyermark; P.E. Berry; K. Yatskievych \& B.K. Holst (eds.). Flora of the Venezuelan Guayana. Saint Louis, Missouri Botanical Garden Press.

Bohs, L. 1994. Cyphomandra (Solanaceae). Flora Neotropica Monograph 63. New York, The New York Botanical Garden.

Bohs, L. 1995. Transfer of Cyphomandra (Solanaceae) and its species to Solanum. Taxon 44: 583-587.

Bohs, L. 2005. Major clades in Solanum based on $n d h \mathrm{~F}$ sequences. Pp. 27-49. In: R.C. Keating; V.C. Hollowell \& T.B. Croat (eds.). A festschrift for William G. D'Arcy: the legacy of a taxonomist. Monographs in Systematic Botany from the Missouri Botanical Garden, v. 104. St. Louis, Missouri Botanical Garden Press.

Brummitt, R.K. \& Powell, C.E. 1992. Authors of Plant Names. Kew, Royal Botanic Gradens.

Cabral, S.M. \& Agra, M.F. 1999. Flora da Paraíba: Olacaceae Mirb. ex DC. Revista Nordestina de Biologia 13: 1-11.

Carvalho, F.A.F. \& Carvalho, M.G.F. 1985. Vegetação. Pp. 34-43. In: Governo do Estado da Paraíba (ed.). Atlas Geográfico do Estado da Paraíba. João Pessoa, Secretaria da Educação. ed. Grafset.

Carvalho, L.d'A.F. 1985. Flora fanerogâmica da reserva do parque estadual das Fontes do Ipiranga, São Paulo, Brasil. Solanaceae. Hoehnea 12: 67-85.

Carvalho, L.d'A.F. 1996. Espécies de Solanum das seções Cernuum Carv. \& Sheph. e Lepidotum (Dun.) Seithe v Holf. (Solanaceae). Pesquisas Botânica 46: 5-83.

Carvalho, L.d'A.F. \& Bovini, M.G. 2006. Solanaceae na Reserva Rio das Pedras, Mangaratiba, Rio de Janeiro, Brasil. Rodriguésia 57: 75-98.

D’Arcy, W.G. 1973. Solanaceae. Pp. 573-780. In: R.E. Woodson \& R.W. Schery (eds.). Flora of Panama. Annais Missouri Botanical Garden, v. 60. 
D'Arcy, W.G. 1991. The Solanaceae since 1976, with a review of its biogeography. Pp. 75-135. In: J.G. Hawkes; R.N. Lester; M. Nee \& N. Estrada (eds.). Solanaceae III: taxonomy, chemistry, evolution. Royal Botanic Gardens, Kew and Linnean Society of London.

Dunal, M.F. 1852. Solanaceae. In: A.C. De Candolle (ed.). Prodromus Systematis Naturalis Regni Vegetabilis 13: 1-690.

Edmonds, J.M. 1972. A Synopsis of the taxonomy of Solanum sect Solanum (Maurella) in South America. Kew Bulletin 27: 95-114.

Edmonds, J.M. 1977. Taxonomics studies of Solanum sect Solanum (Maurella). Botanical Journal of the Linnean Society 75: 141-178.

Holmgren, P.K.; Holmgren, N.H. \& Barnett, L.C. 1990. Index Herbariorum. Part I. The Herbaria of the World. 8 ed. USA, The New York Botanical Garden Press.

Hunziker, A.T. 2001. The genera of Solanaceae. A.R.G. Gantner Verlag K.-G.

Knapp, S. 1989. Six New Species of Solanum sect. Geminata from South America. Bulletin of the British Museum Natural History (Botany) 19: 103-112.

Knapp, S. 2002. Solanum section Geminata (Solanaceae). Flora Neotropica 84: 1-404.

Lester, R.N.; Francisco-Ortega, J. \& Al-Ani, M. 1999. Convergent evolution of heterandry (unequal stamens) in Solanum, proved by spermoderm SEM. Pp. 51-69. In: M. Nee; D.E. Symon; R.N. Lester \& J.P. Jessop (eds.). Solanaceae IV: Advances in Biology and Utilization. Kew, Royal Botanic Gardens.

Levin, R.A.; Myers, N.R. \& Bohs, L. 2006. Phylogenetic relationships among the "spiny Solanums" (Solanum subgenus Leptostemonum, Solanaceae). American Journal Botany 93: 157-169.

Lima, P.J. \& Heckendorff, W.D. 1985. Climatologia. Pp. 34-43. In: Governo do Estado da Paraíba (ed.). Atlas geográfico do Estado da Paraíba. Secretaria da Educação, ed. Grafset, João Pessoa.

Linnaeus, C. 1753. Genera Plantarum. v.1. Stockholm.

Loiola, M.I.B.; Agra, M.F.; Baracho, G.S \& Queiroz, R.T. 2007. Flora da Paraíba, Brasil: Erythroxylaceae Kunth. Acta Botanica Brasilica 21: 473-487.

Mentz, L.A. \& Nee, M. 2003a. Solanum setosissimum (Solanaceae), espécie nova para os estados do Paraná e Santa Catarina, Brasil. Pesquisas Botânica 53: 163-167.

Mentz, L.A. \& Nee, M. 2003b. Solanum aparadense (Solanaceae), espécie nova para a região dos Aparados Da Serra, sul do Brasil. Pesquisas Botânica 53: 169-174.

Mentz, L.A. \& Oliveira, P.L. 2004. Solanum (Solanaceae) na região sul do Brasil. Pesquisas Botânica 54: 9-327.

Moreira, E.R.F. 1985. Situação e localização. Pp. 12-15. In: Governo do Estado da Paraíba (ed.). Atlas geográfico do Estado da Paraíba. Secretaria da Educação. João Pessoa, ed. Grafset.

Nee, M. 1979. Patterns in biogeography in Solanum, section Acanthophora. Pp. 569-580. In: J.G. Hawkes; R.N. Lester \& A.D. Skelding (eds.). The Biology and Taxonomy of the Solanaceae. London, Academic Press.
Nee, M. 1991. Synopsis of Solanum section Acanthophora: a group of interest for glycoalkaloids. Pp. 257-266. In: J.G. Hawkes; R.N. Lester; M. Nee \& N. Estrada (eds.). Solanaceae III: taxonomy, chemistry, evolution. Royal Botanic Gardens, Kew and Linnean Society of London.

Nee, M. 1999. Synopsis of Solanum in the New World. Pp. 285-333. In: M. Nee; D.E. Symon; R.N. Lester \& J.P. Jessop (eds.). Solanaceae IV: Advances in Biology and Utilization. Kew, Royal Botanic Gardens.

Nurit, K. \& Agra, M.F. 2005. Estudo farmacobotânico comparativo entre Nicandra physalodes e Physalis angulata (Solanaceae). Revista Brasileira de Farmacognosia 15: 344-51.

Nurit, K.; Agra, M.F.; Basílio, I.J.L.D. \& Baracho, G.S. 2005. Flora da Paraíba, Brasil: Loganiaceae. Acta Botanica Brasilica 19: 407-416.

Nurit, K.; Agra, M.F.; Basílio, I.J.L.D. \& Baracho, G.S. 2007a. Estudo Farmacobotânico de Folhas de Nicotiana glauca (Solanaceae). Latin American Journal of Pharmacy 26: 499-506.

Nurit, K.; Agra, M.F. \& Basílio, I.J.L.D. 2007b. Estudo farmacobotânico comparativo entre Solanum paniculatum L. e Solanum rhytidoandrum Sendtn (Solanaceae). Revista Brasileira de Biociências 5: 243-245.

Olmstead, R.G.R. \& Palmer, J.D. 1997. Implications for the phylogeny, classification and biogeography of Solanum from cpDNA restriction site variation. Systematic Botany 22: 19-29.

Olmstead, R.G.R.; Sprangler, E.; Bohs, L. \& Palmer, J.D. 1999. Phylogeny and provisional classification of the Solanaceae based on chloroplast DNA. Pp. 111-138. In: M. Nee \& D.E. Symon (eds.). Solanaceae IV: advances in biology and utilization. Kew, Royal Botanic Gardens.

Pontes, A.F.; Barbosa, M.R.V. \& Maas, P.J.M. 2004. Flora Paraibana: Annonaceae Juss. Acta Botanica Brasilica 18: 281-293.

Pontes, R.A. \& Agra, M.F. 2006. Flora da Paraíba, Brasil: Tillandsia L. (Bromeliaceae). Rodriguésia 57: 47-61.

Roe, K.E. 1972. A Revision of Solanum section Brevantherum (Solanaceae). Brittonia 29: 239-278.

Sendtner, O. 1846. Solanaceae, Cestrinae. Pp. 1-227. In: C.F.P. von Martius (ed.). Flora brasiliensis. Wolf, Munich, Germany. v.10.

Smith, L.B. \& Downs, R.J. 1966. Solanáceas. Pp. 1-321. In: P.R. Reitz (ed.). Flora Ilustrada Catarinense. Itajaí, Herbário Barbosa Rodrigues.

Sousa, E.C.; Agra, M.F. \& Nurit, K. 2004. Flora Paraibana: Solanaceae I - Schwenckia L. Revista Nordestina de Biologia 18: 18-28.

Spooner, D.M.; Castillo, R. \& Lopez, L.E. 1993. Synonymy within wild potatoes (Solanum sect. Petota: Solanaceae): the case of Solanum andreanum. Systematic Botany 18: 209-217.

Stannard, B.L. 1995. Solanaceae. Pp. 593-602. In: B.L. Stannard (ed.). Flora of the Pico das Almas, Chapada Diamantina, Bahia, Brazil. Kew, Royal Botanic Gardens.

Whalen, M.D.; Costich, D.E. \& Heiser-Jr., C.B. 1981. Taxonomy of Solanum section Lasiocarpa. Gentes Herbarum 12: 41-129.

Whalen, M.D. 1984. Conspectus of species groups in Solanum subgenus Leptostemonum. Gentes Herbarum 12: 179 - 292. 